UNIVERSIDADE DE SÃO PAULO

PROGRAMA INTERUNIDADES DE PÓS-GRADUAÇÃO EM BIOINFORMÁTICA

Yuri Ferretti

Ferramenta Computacional para Análise Integrada de Dados Clínicos e Biomoleculares

Ribeirão Preto

2015 


\section{Yuri Ferretti}

Monografia apresentada ao Programa Interunidades de Pós-Graduação em Bioinformática da Universidade de São Paulo para obtenção do grau de Mestre em Ciências.

Área de Concentração: Bioinformática

Orientador : Prof. Dr. Joaquim Cezar Felipe, jfelipe@ffclrp.usp.br

Ribeirão Preto

2015 


\section{Ferramenta Computacional para Análise Integrada de Dados Clínicos e Biomoleculares}

Este exemplar corresponde à versão original da dissertação de Mestrado do aluno Yuri Ferretti. 
Banca Examinadora:

- Geraldo Aleixo da Silva Passos Júnior

- Prof. Dr. Ricardo Rodrigues Ciferri

- Prof. Dr. Joaquim Cezar Felipe 
Aos meus pais Humberto e Maria Aparecida, ao meu irmão Yann por todo o suporte, amor e paciência 


\section{AGRADECIMENTOS}

Agradeço primeiramente a Deus por me dar oportunidade e forças para conseguir atingir mais um objetivo e progredir em minha vida.

Aos meus pais Humberto e Maria Aparecida e ao meu irmão Yann, por serem portos seguros nos quais eu posso confiar a cada segundo da minha existência e por me ajudarem nos momentos que mais precisei.

Aos meus colegas de laboratório, Newton, Marlon, Mariana, Rômulo e Samuel por compartilharem comigo ótimos momentos vividos durante o curso desse mestrado.

Ao meu orientador, Joaquim, por me dar esta oportunidade de desenvolvimento acadêmico, pela confiança e paciência depositadas em mim e no meu trabalho.

Ao Programa Interunidades em Bioinformática por todo o apoio prestado.

À CAPES pelo apoio financeiro. 


\section{Resumo}

A massificação dos estudos da medicina translacional permite aos pesquisadores que usufruam de fontes de dados das mais diversas áreas. Uma área de suma importância é a bioinformática, que agrega o alta capacidade de processamento computacional disponível atualmente, com a infindável quantidade de dados gerada por métodos de sequenciamento de última geração, para entregar aos pesquisadores uma quantidade rica de dados para serem analisados. Apesar da disponibilidade desses dados, a expertise necessária para analisá-los dificulta que profissionais com pouco conhecimento em bioinformática, estatística e ciência da computação possam realizar pesquisas e análises com estes dados. Dada esta situação, este trabalho consistiu em criar uma ferramenta que tira proveito da integração de múltiplas bases de dados proporcionada pelo framework IPTrans, permitindo que usuários da área biomédica realizem análises com os dados contidos nessas bases. Com base em outras ferramentas existentes e em um levantamento de requisitos junto a potenciais usuários, foram identificadas as funcionalidades mais importantes e assim foi projetada e implementada a IPTrans Advanced Analysis Tool (IPTrans A2Tool). Esta ferramenta permite que usuários façam análises de expressão diferencial mais comuns como heatmaps, volcano plots, consenso de agrupamentos e blox-plot. Além disso, a ferramenta proporciona um algoritmo de mineração de dados baseado na extração de regras de associação entre dados clínicos e biomoleculares, que permite ao usuário descobrir novas associações entre a expressão dos genes dados clínicos e fenotípicos. Adicionalmente a este trabalho, foi criado também o BioBank Warden, um sistema de controle de dados clínicos e amostras biomoleculares, que foi utilizado como uma das fontes de dados para o IPTrans A2Tool. Este sistema permite que usuários adicionem informações clínicas de pacientes e também das amostras extraídas para a realização de estudos. Uma avaliação preliminar de usabilidade, realizada junto a profissionais da área biomédica, mostrou que as ferramentas possuem potencial para serem utilizadas no contexto da medicina translacional. 


\section{Abstract}

The great number of translational medicine studies allows researchers to make benefit of data sources from various fields. An area of great importance is bioinformatics, which combines the high computational processing capabilities found nowadays with the endless amount of data generated by next-generation sequencing methods, to give researchers a rich amount of data to be analyzed. Despite the availability of such data, the expertise required to analyze it makes difficult for professionals with little knowledge in bioinformatics, statistics or computer science, to conduct research and analysis on this data. Given this situation, this work was intended to create a tool that takes advantage of multiple databases integration capabilities provided by IPTrans and that allows users to perform analysis on the data contained in these databases. To accomplish that other tools were studied in order to observe which features our framework should aggregate and thus was created the IPTrans A2Tool (IPTrans Advanced Analysis Tool). This tool allows users to perform differential expression analysis and generate output as heatmaps, volcano plots, consensus clustering and blox-plots. In addition, the tool provides an association rule extraction algorithm between clinical and biomolecular data, allowing the user to discover hidden associations between the expression of analyzed genes and clinical data. As a by-product of this work was also created the BioBank Warden a clinical data and biomolecular samples management system that was used as one of the data sources for IPTrans A2Tool. This system allows users to add patients' clinical information and also of samples taken for carrying out studies. In addition, the system provides a strong research group and project permission management that ensures only authorized people to have access to patients' data. 


\section{Sumário}

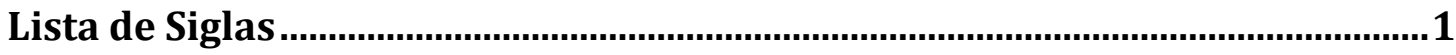

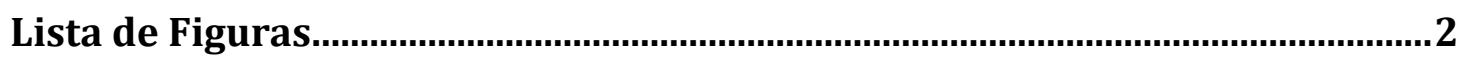

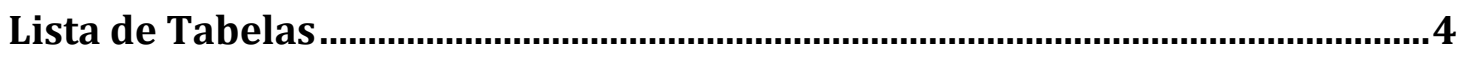

Capítulo 1 Introdução......................................................................................... 1

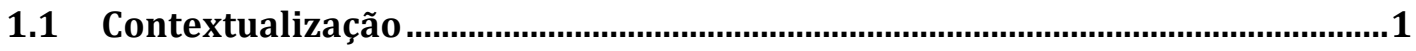

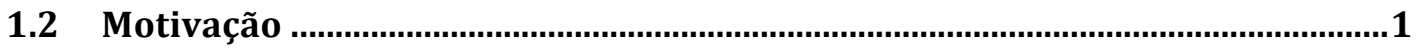

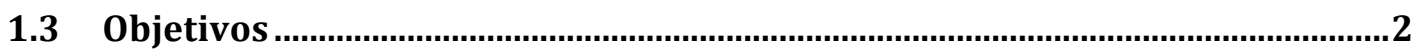

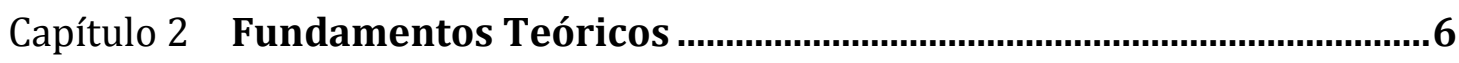

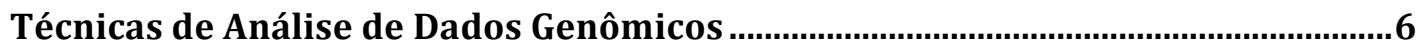

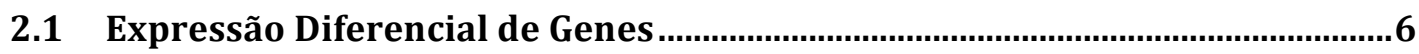

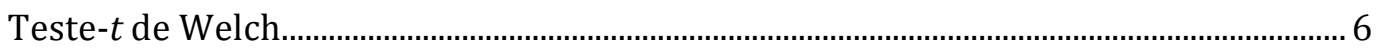

FDR (False Discovery Rate) Benjamini/Hochberg ............................................................ 8

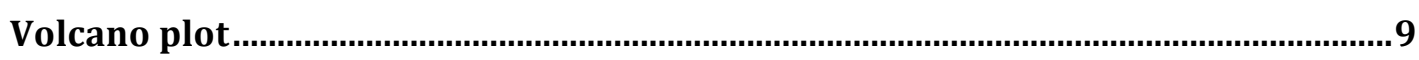

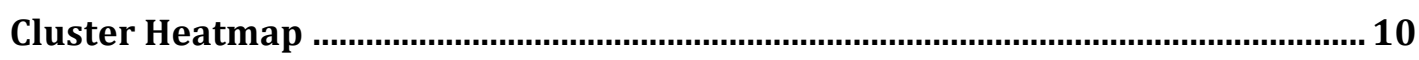

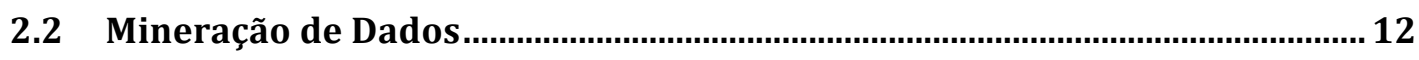

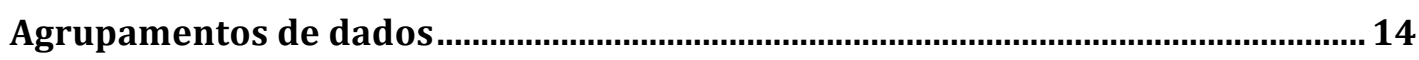

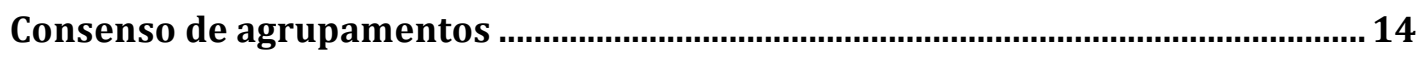

Regras de Associação .......................................................................................................... 14

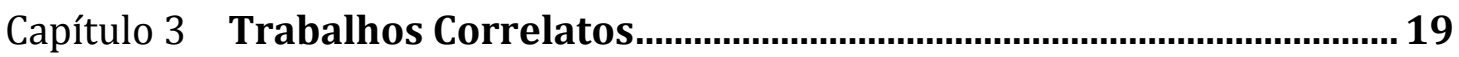

3.1 Oncomine

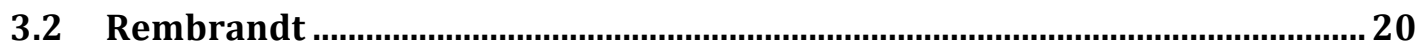

3.3 Firehose

Capítulo 4 Proposta do Framework de Análise …................................................. 26

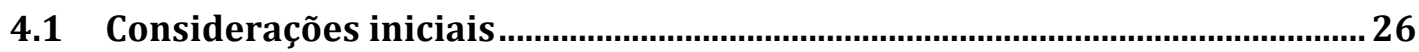

4.2 IPTrans (Integrative Platform for Translational Research) ........................... 23

4.2.1 Arquitetura do IPTrans......................................................................................... 23

4.2.2 Níveis do sistema.............................................................................................. 24

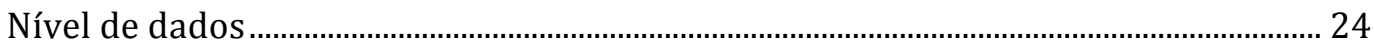

Nível semântico …………………………………………………………………………..... 25 
Nível de aplicação

Nível de interface web ................................................................................................... 25

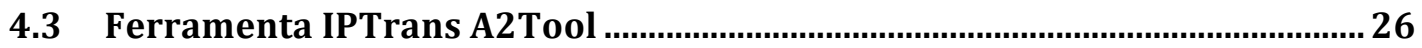

4.3.1 Arquitetura da ferramenta IPTrans A2Tool ………………………………….... 26

4.3.2 Funcionalidades do IPTrans A2Tool...................................................................... 28

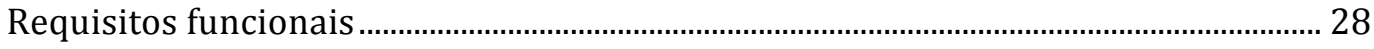

Requisitos não funcionais ............................................................................................. 30

4.3.3 Casos de Uso do IPTrans A2Tool ........................................................................... 30

4.3.4 Diagrama Entidade Relacionamento IPTrans A2Tool........................................ 33

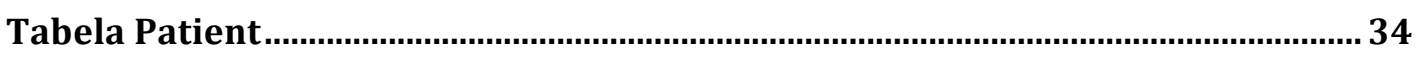

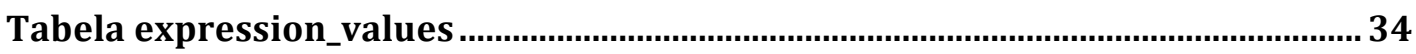

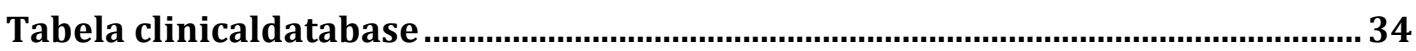

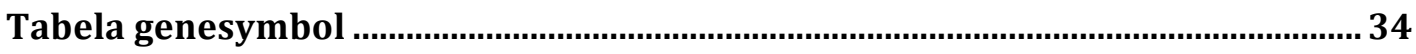

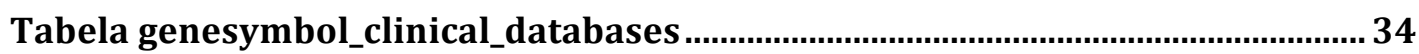

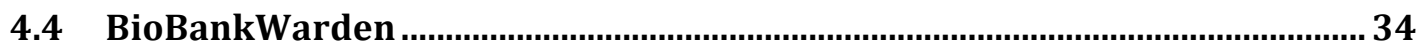

4.4.1 Requisitos funcionais....................................................................................... 34

Gerenciamento de materiais biológicos..............................................................................................

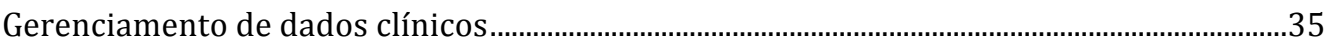

Gerenciamento de grupos e papéis de usuários ....................................................................35

4.4.2 Requisitos não funcionais................................................................................ 36

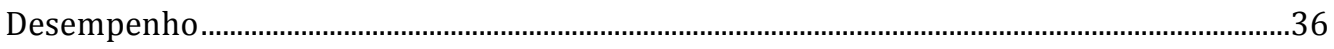

Usabilidade

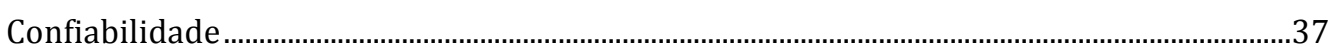

4.4.3 Casos de uso BioBank Warden ............................................................................. 37

4.4.4 Diagrama Entidade Relacionamento BioBank Warden ....................................... 42

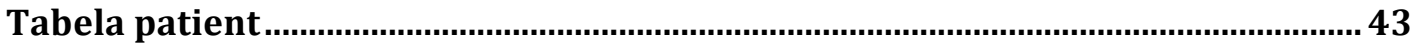

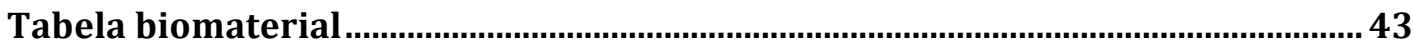

Tabela survey

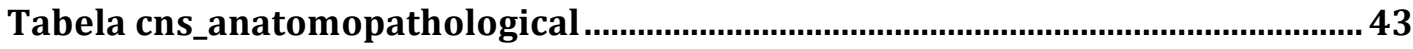

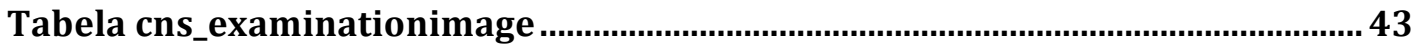

Tabela cns_clinicallaboratory

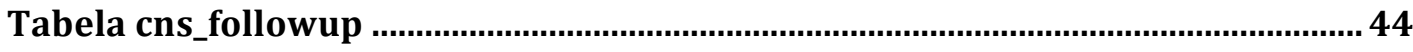

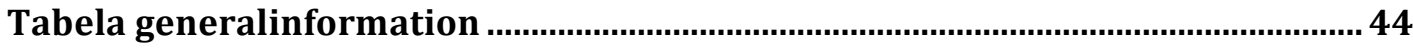

4.5 Integração do framework IPTrans A2Tool e BioBank Warden ..................... 44

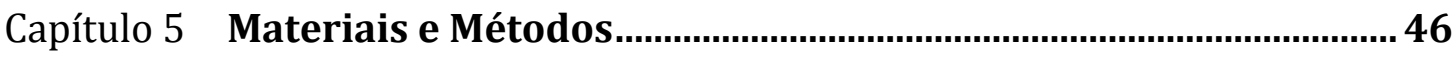

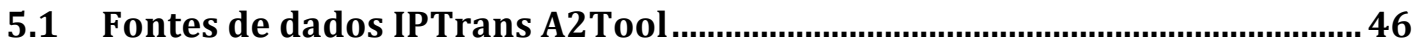


5.2 Fontes de dados Biobank Warden

5.3 Metodologia de desenvolvimento dos sistemas ...............................................47

5.4 Plataformas e ferramentas de desenvolvimento ..............................................48

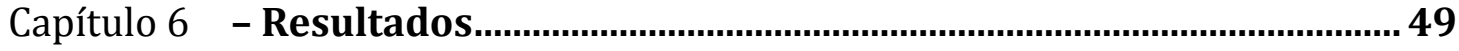

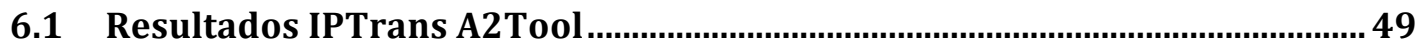

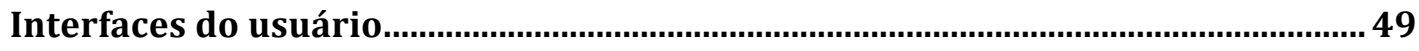

Avaliação de usabilidade dos usuários .................................................................... 53

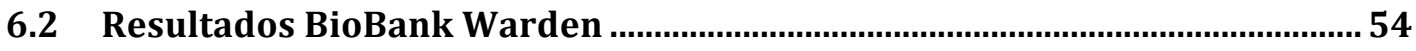

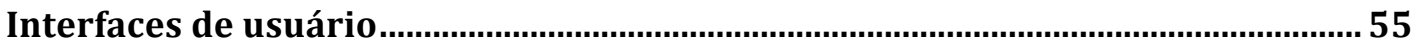

Avaliação de usabilidade dos usuários ........................................................................59

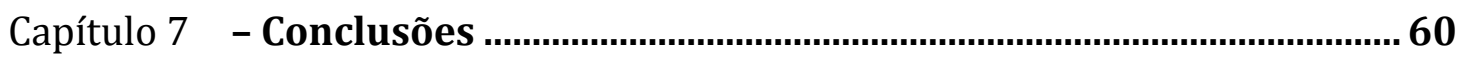

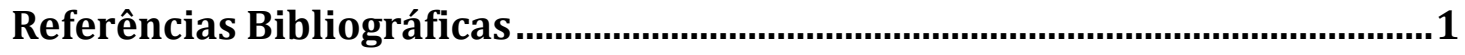




\section{Lista de Siglas}

$\begin{array}{ll}\text { IPTrans } & \text { Integrative Platform for Translational Research } \\ \text { EAV } & \text { Entidade Atributo Valor } \\ \text { FMRP } & \text { Faculdade de Medicina de Ribeirão Preto } \\ \text { USP } & \text { Universidade de São Paulo } \\ \text { SNC } & \text { Sistema Nervoso Central } \\ \text { NAP } & \text { Núcleo de Apoio à Pesquisa } \\ \text { CISBi } & \text { Center for Integrative System Biology } \\ \text { GO } & \text { Gene Ontology } \\ \text { mRNA } & \text { Ácido Ribonucleico Mensageiro } \\ \text { miRNA } & \text { Micro Ácido Ribonucleico } \\ \text { RNAseq } & \text { Sequenciamento de Ácido Ribonucleico } \\ \text { miRseq } & \text { Sequenciamento de Micro Ácidos Ribonucleicos }\end{array}$




\section{Lista de Figuras}

Figura 1 Exemplo de volcano plot de expressão gênica. Pode-se ver os genes sub-expressos em azul e os genes super-expressos em vermelho

Figura 2 Heatmap sem agrupamento de colunas na esquerda e com agrupamento de colunas por similaridade na direita.

Figura 3 Heatmap de expressão gênica evidenciando a diferença de expressão do grupo de genes selecionados para pacientes controle, na esquerda , versus pacientes com câncer na direita 11

Figura 4 - Distribuição de amostras por subtipo de câncer. A parte mais escura do gráfico representa as novas amostras inseridas na ultima atualização da base de dados. Extraída de: www.oncomine.org/resource/main.html fevereiro de 2014

Figura 5 Arquitetura multicamadas do sistema IPTrans A2Tool.

Figura 6 Caso de uso para obtenção de heatmap de expressão diferencial.

Figura 7 Caso de uso exemplificando os passos realizados para gerar um volcano plot de expressão gênica diferencial.

Figura 8 Figura exibindo o diagrama de caso de uso para obtenção de gráficos de agrupamento consenso.

Figura 9 Figura ilustrando o diagrama de caso de uso para mineração de regras de associação entre dados clínicos e biomoleculares.

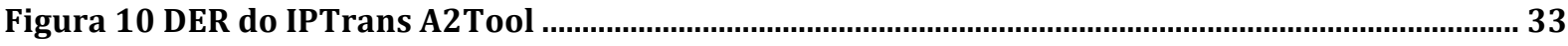

Figura 11 Diagrama de caso de uso para acesso as seções privadas do sistema. ................................. 37

Figura 12 Diagrama de caso de uso para inserção de um novo paciente no sistema........................... 38

Figura 13 Diagrama de caso de uso para edição de dados de um paciente. ...................................... 39

Figura 14 Diagrama de caso de uso para inserção de um novo formulário de dados para um paciente selecionado pelo usuário. 39

Figura 15 Diagrama de caso de uso para inserção de um novo biomaterial...................................... 40

Figura 16 Diagrama de caso de uso para requisição de biomaterial. ....................................................41

Figura 17 Diagrama entidade relacionamento das principais tabelas do sistema BioBank Warden.

Figura 18 - Interface de seleção de base de dados e análises. ................................................................ 50

Figura 19 Tabela com dados para cada gene utilizado na análise ..................................................... 51

A seguir, a figura 20 exibe a interface com gráficos para heatmap expressão diferencial e volcano plots.

Figura 20 Interface com os gráficos para heatmap e volcano plot.

Figura 21 - Interface de configuração do algoritmo de extração de regras de decisão.

Figura 22 - Regras obtidas para todos os dados cujos pacientes eram portadores de câncer de mama. 
Figura 23 - Interface de listagem de pacientes

Figura 24 Interface de inserção de dados clinico-laboratoriais. 56

Figura 25 - Interface mostrando a listagem de biomateriais............................................................... 57

Figura 26 - Interface de requisição de alíquota de biomaterial...................................................... 58

Figura 27 - interface detalhando as informações do biomaterial. Na esquerda está presente uma árvore composta pelo biomaterial e suas sub-alíquotas. ................................................................ 58 


\section{Lista de Tabelas}

Tabela 1 - Quantidade de erros cometidos quando testando m hipóteses nulas 8

Tabela 2 - Números de experimentos armazenados pelo Rembrandt . Última atualização em

$27 / 07 / 2010$ 21

Tabela 3 - Quantidade de dados por tipo de amostra no Firehose em janeiro de 2014. 22

Tabela 4 - Comparativo de funcionalidades entre o IPTrans A2Tool e as ferramentas estudadas. 29

Tabela 5 - Tabela com as respostas de cada usuário para o questionário de usabilidade. 54

Tabela 6 - Tabela com os resultados obtidos para cada usuário que respondeu o questionário.... 59 


\section{Capítulo 1 Introdução}

\subsection{Contextualização}

Como consequência do mapeamento do genoma humano e da chegada de novas técnicas de sequenciamento, pesquisadores de doenças oncológicas têm realizado um grande progresso no estudo e na compreensão do desenvolvimento do câncer. Entres os esforços recentes, pode-se incluir a medicina translacional, que consiste na integração das ciências básicas, sociais e políticas para otimizar o tratamento de pacientes, bem como a descoberta de novas medidas preventivas por meio de descobertas de fatores ambientais e comportamentais que possam causar mutações em nosso código genético e estimular o desenvolvimento do câncer (FELDMAN, 2008).

$\mathrm{O}$ aumento das pesquisas na área médica envolvendo dados clínicos e biomoleculares vem gerando um contingente extenso de bases de dados legadas, cujos conteúdos são determinados por objetivos específicos de pesquisa. Esta quantidade de bases de dados específicas cria dificuldades na integração, intercâmbio e reaproveitamento de dados por parte de pesquisadores que necessitem usá-los (PAYNE, 2005). No entanto, a proposta da medicina translacional pressupõe que o maior número possível de dados estejam disponíveis para uso, a fim de permitir o melhor prognóstico possível para os pacientes, e por este motivo passa a ser de total importância prover uma forma de integrar e disponibilizar dados de diferentes fontes tornando mais fácil a atividade do pesquisador (MCCONELL, 2008).

\subsection{Motivação}

Várias propostas visando facilitar a análise da informação biomolecular podem ser encontradas, como, por exemplo, os sistemas Scientific Laboratory Information Management - Patient-care Research Information Management (Slim Prim), mantido pela Universidade do Tennessee (VIANGTEERAVAT, 2009); Stanford Translational Research Integrated Database Environment (STRIDE), desenvolvido pela Universidade de Stanford (LOWE, 2009); Informatics for Integrating Biology and the Bedside (I2B2) mantido pelo National Center for Biomedical Computing dos Estados Unidos (MURPHY 
2007); A C. elegans Database (AceDB) (STEIN, 1999); e finalmente, Ensembl (HUBBARD, 2002).

Dentre os trabalhos focados na padronização e integração das informações para medicina translacional, Myioshi et. al (MIYOSHI, 2013) propuseram um framework de integração de dados clínicos com dados biomoleculares por meio do uso de uma ontologia de referência, denominado de Integrative Plataform for Translational Research (IPTrans). 0 projeto do framework é composto de quatro camadas: camada de dados, responsável pelo armazenamento dos dados; camada semântica, responsável pelo integração e padronização dos dados por meio do uso de ontologias; camada de aplicação, responsável pelo gerenciamento de bases de dados integradas, ontologias e processo de integração dos dados; camada de interface, responsável pela interação entre o usuário e o framework. Para a estruturação dos dados clínicos a serem integrados, o framework se baseia no modelo Entidade-Atributo-Valor (EAV), que faz uso de listas de associações representativas de informações que estejam relacionadas a cada objeto utilizando-se de pares atributo-valor.

Embora o IPTrans permita a integração dos dados de forma robusta e possua alguns métodos de visualização dos dados armazenados em sua base, o aproveitamento efetivo de suas funcionalidades para as pesquisas em medicina translacional se dará a partir da implementação de metodologias avançadas de análise de dados.

\subsection{Objetivos}

Dadas as características do IPTrans, o presente trabalho consistiu no projeto e implementação da IPTrans Advanced Analysis Tool (A2Tool), uma ferramenta que tira proveito de toda a capacidade de armazenamento e integração provida pelo framework IPTrans, oferecendo funcionalidades que permitem aos pesquisadores na área da medicina translacional realizar análises avançadas sobre os dados de suas pesquisas sem a necessidade de expertise em bioinformática e de forma mais simples.

No campo da análise de dados, contamos com diferentes formas de análise que são realizadas com dados clínicos e dados biomoleculares separadamente. Com os dados clínicos pode-se efetuar: estudos temporais da evolução do quadro do paciente; classificação por meio de aprendizado de máquina, normalmente utilizado para criar técnicas de auxílio ao diagnóstico; busca por características comumente presentes em pacientes com um mesmo quadro; entre outras. Já com os dados biomoleculares é 
possível realizar: análise de níveis de expressão gênica; identificação de mutações que desencadeiem uma determinada condição; aconselhamento genético com o intuito de se estabelecer uma probabilidade de descendentes portarem determinadas mutações. Dado esse diversificado contexto de análises, torna-se importante a implementação de métodos estatísticos e computacionais que permitam analisar os dados clínicos e os dados biomoleculares de forma integrada, possibilitando assim novas descobertas que mostrem aos cientistas as relações existentes entre características clínicas (assim como epidemiológicas) e informações genéticas.

$\mathrm{Na}$ etapa inicial de desenvolvimento do IPTrans A2Tool, algumas ferramentas robustas criadas para analisar a expressão gênica de doenças relacionadas ao câncer foram investigadas. A ferramenta chamada Oncomine (RHODES, 2004) foi inicialmente desenvolvida pela universidade de Michigan e, após o ano de 2006, teve sua versão comercial estabelecida após a fundação do Compendia Bioscience, que é responsável pela sua manutenção até o presente momento. O Oncomine é uma plataforma que contém dados de microarray relacionados a diversos tipos de câncer. Entre suas capacidades estão: visualização e análises integradas relativas a genes ou conjuntos de genes; maior facilidade para descobrir novos biomarcadores ou alvos terapêuticos por meio da seleção de anotações contendo características como interação droga-gene. Outra ferramenta já consolidada é o Repository for Molecular Brain Neoplasia Data (REMBRANDT), que armazena dados de doenças cancerígenas do sistema nervoso central e permite aos usuários analisar estatisticamente os dados contidos na base, além de permitir a criação e visualização de relatórios que contenham os resultados dessas análises (MADHAVA, 2007). Finalmente, podemos citar Firehose como outra ferramenta de análise integrada de dados clínicos e biomoleculares criada pelo The Cancer Genome Atlas. Esta ferramenta permite ao usuário criar pipelines de análise e processamento dos dados, além de contar com algoritmos de associação entre características clínicas e biomoleculares. Estas ferramentas serão descritas com mais detalhes no capítulo 3. No capítulo 4 é apresentado um quadro comparativo dos recursos disponíveis.

A partir da avaliação da utilidade dos diversos recursos oferecidos por ferramentas de análise existentes, juntamente com o levantamento de outros recursos considerados relevantes por usuários especialistas, foram definidas as principais funcionalidades implementadas pelo IPTrans A2Tool, que são: 
- Seleção dos dados - a ferramenta permite que os dados extraídos da base do IPTrans sejam filtrados, possibilitando que o usuário selecione apenas os conjuntos de dados relevantes para suas análises específcas;

- Visualização dos dados - o IPTrans A2Tool possui um conjunto de gráficos que visam facilitar o entendimento dos dados por parte do usuário, tais como heat tmaps, dendrogramas, volcano plots, box plots e matrizes de agrupamentos hierárquicos;

- Associação de dados clínicos e biomoleculares - por meio de técnicas de mineração de dados, o IPTrans A2Tool permite a descoberta de correlações ocultas entre dados clínicos e biomoleculares;

- Comparação de expressão gênica usando análise diferencial - o IPTrans A2Tool conta com métodos que permitem ao usuário comparar níveis de expressão gênica entre dois grupos de indivíduos, além de também permitir a comparação da expressão utilizando dados clínicos como parâmetros;

- Exportação dos dados - todos os resultados provenientes do IPTrans A2Tool podem ser exportados em diferentes formatos para facilitar o uso dos mesmos por parte dos pesquisadores.

Nenhuma das ferramentas correlatas aqui citadas disponibilizam todas estas funcionalidades juntas, propostas para o IPTrans A2Tool.

Em conjunto com o IPTrans A2Tool foi desenvolvido um sistema de gerenciamento e integração de dados clínicos e biomoleculares denominado Biobank Warden. Este sistema tem como propósito:

1. Permitir o armazenamento, consulta e gerenciamento de informações clínicas e de amostras biomoleculares de pacientes de oncologia;

2. Atuar como uma base legada de testes e validação para o IPTrans A2Tool.

Para ambos os sistemas, foram levantados os requisitos junto a um grupo de possíveis usuários e, a partir daí, foi realizado um processo iterativo de construção de protótipos, avaliação dos mesmos pelos usuários, refinamento, testes e validação. Para a validação, alguns usuários responderam um questionário para avaliar o grau de usabilidade do sistema.

As realizações deste trabalho estão descritas nos próximos capítulos deste documento. Capítulo 2: Fundamentos Teóricos; Capítulo3: Trabalhos Correlatos, onde 
serão mostrados os trabalhos encontrados na literatura que ajudaram a delinear a pesquisa realizada; Capítulo 4: Proposta do framework de análise, que apresentará a proposta de desenvolvimento das ferramentas IPTrans A2Tool e Biobank Warden; Capítulo 5: Materiais e métodos, onde serão mostrados como a ferramenta foi desenvolvida; Capítulo 6: Resultados, no qual serão apresentados os resultados obtidos; Capítulo 7: Discussões e conclusões. 


\section{Capítulo 2 Fundamentos Teóricos}

\section{Técnicas de Análise de Dados Genômicos}

Atualmente, as técnicas que produzem dados genômicos, como microarrays e next-generation sequencing, permitem aos pesquisadores obter informações de expressão gênica de milhares de genes de uma única vez, gerando, para isto, uma elevada quantidade de dados. Esta grande quantidade de dados requer que técnicas automatizadas baseadas em testes estatísticos e aprendizado de máquina sejam utilizadas para que os pesquisadores possam analisar os dados de forma amigável, rápida e confiável. Neste capítulo serão descritas algumas das técnicas estatísticas e computacionais utilizadas para análise de dados genômicos.

\subsection{Expressão Diferencial de Genes}

Um importante problema comumente encontrado em experimentos de microarrays é a identificação de genes diferencialmente expressos, isto é, genes cujos níveis de expressão estão associados com uma determinada resposta ou variável de interesse. Estas variáveis podem compreender respostas a tratamentos com drogas, tipo ou função da célula e situação do paciente como caso ou controle. Estes tipos de experimentos, em geral, buscam comparar a quantidade de transcrito em duas amostras de RNAm.

Para descobrimos quais genes estão diferencialmente expressos são realizados testes estatísticos para cada gene. No presente trabalho utilizaremos uma variação do teste-t de Welch, pois estaremos comparando duas classes de amostras como caso versus controle, ou ausência versus presença de determinadas características clínicas e também permitiremos variâncias distintas entre os dois grupos.

\section{Teste- $t$ de Welch}

O teste de Welch, ou teste- $t$ de Welch é um teste estatístico usado para testar a hipótese de que duas populações possuem médias iguais. Este teste é uma adaptação do test- $t$ de Student que se mostra mais confiável quando as populações possuem variâncias e tamanhos de amostras discrepantes. (FAGERLAND, 2012). 
Para definir o teste- $t$ de Welch podemos considerar duas populações $C_{1}$ e $C_{2}$ que seguem distribuições normais $N\left(\mu_{1} \sigma_{1}^{2}\right)$ e $N\left(\mu_{2} \sigma_{2}^{2}\right)$. Desta forma a estatística para o teste- $t$ de Welch pode ser obtida por meio da equação 1:

$$
t=\frac{\bar{X}_{1}-\bar{X}_{2}}{\sqrt{\frac{s_{1}^{2}}{N_{1}}+\frac{s_{2}^{2}}{N_{2}}}}
$$

na qual $\bar{X}_{1}$ e $\bar{X}_{2}$ são as médias, $s_{1}^{2}$ e $s_{2}^{2}$ são as variâncias e $N_{1}$ e $N_{2}$ são os tamanhos das amostras $\mathrm{C}_{1}$ e $\mathrm{C}_{2}$, respectivamente.

Os graus de liberdade podem ser calculados de acordo com a equação WelchSatterthwaite:

$$
v \approx \frac{\left(\frac{s_{1}^{2}}{N_{1}}+\frac{s_{2}^{2}}{N_{2}}\right)^{2}}{\frac{s_{1}^{4}}{N_{1}^{2} v_{1}}+\frac{s_{2}^{4}}{N_{2}^{2} v_{2}}}
$$

onde $v_{1}=N_{1}-1$ graus de liberdade associados ao estimador de variância de $C_{1} \mathrm{e}$, $v_{2}=N_{2}-1$ graus de liberdade associados ao estimador de variância de $C_{2}$.

A partir destas definições podemos considerar duas hipóteses: $H_{0}$ que nos diz que não existe diferença entre as médias das populações $C_{1}$ e $C_{2} ; H_{1}$ que nos diz que as médias das populações $C_{1}$ e $C_{2}$ são distintas. Também deve ser definido um nível de significância $p$ ou $p$-valor $\left(p_{\min }\right) r$, ou seja, a probabilidade de refutarmos $H_{0}$ quando ela for verdadeira. Para testar qual hipótese é válida, calcula-se o valor de $t$ e $v$, e, a partir de softwares ou tabelas com valores computados, podemos obter o $p$-valor calculado $\left(p_{\text {calc }}\right)$. Desta forma,

$$
\left\{\begin{array}{c}
\text { se } p_{\text {calc }}<p_{\text {min }}, \text { então } H_{0} \text { é falsa } \\
\text { senão } H_{0} \text { é verdadeira }
\end{array}\right.
$$

Se $H_{0}$ for refutada, então podemos afirmar que existe uma diferença estatisticamente significativa e que as médias das duas populações são distintas. 


\section{FDR (False Discovery Rate) Benjamini/Hochberg}

No caso da análise de expressão diferencial entre genes, normalmente milhares de testes são realizados de forma simultânea, já que em experimentos de microarray, podem ser obtidos dados de mais de 10.000 genes de uma vez. Este grande número de testes aumenta a quantidade de falsos positivos, ou seja, rejeitarmos a hipótese $H_{0}$ quando ela for verdadeira. Por isso, é necessário que os $p$-valores encontrados sejam ajustados para que possam mostrar de fato a significância estatística dos testes. A forma que utilizamos neste trabalho para ajustar os $p$-valores é chamada de análise de FDR (False Discovery Rate), ou seja, analisamos a proporção esperada de erros do tipo I (rejeição $H_{0}$ quando esta é verdadeira). 0 método para análise FDR é o de Benjamini/Hochberg. (BENJAMINI, 1995).

Para entendermos o método FDR consideremos a Tabela 1.

Tabela 1 - Quantidade de erros cometidos quando testando $m$ hipóteses nulas.

\begin{tabular}{|c|c|c|c|}
\hline $\begin{array}{c}\text { Testes declarados } \\
\text { significativos }\end{array}$ & $\boldsymbol{H}_{\mathbf{0}}$ é verdadeira & $\boldsymbol{H}_{\mathbf{1}}$ é verdadeira & Total \\
\hline $\begin{array}{c}\text { Testes declarados } \\
\text { não significativos }\end{array}$ & $U$ & $S$ & $R$ \\
\hline Total & $m_{0}$ & $T$ & $m-R$ \\
\hline
\end{tabular}

onde $m$ é o número total de hipóteses testadas; $m_{0}$ é o número real de hipóteses nulas $\left(H_{0}\right) ; m-m_{0}$ é o número de hipóteses alternativas; $V$ é o número de falsos positivos (erros do tipo I, ou falsas descobertas); $S$ é o número de verdadeiros positivos; $T$ é o número de falsos negativos (erros do tipo II); $U$ é o número de verdadeiros positivos; e $R$ é o número de hipóteses nulas rejeitadas. Neste tipo de experimento, no qual existem $m$ testes de hipóteses, dentre os quais $m_{0}$ são hipóteses nulas verdadeiras; $R$ é uma variável aleatória observável e $S, T, U$ e $V$ são variáveis aleatórias não observáveis.

Desta forma, FDR pode ser definido como:

$$
F D R=\left\{\begin{array}{l}
E\left[\frac{V}{R}\right], \text { se } R>0 \\
0 \text { caso contrário }
\end{array}\right.
$$


Para entendermos o método de controle de FDR proposto por Benjamine/Hochberg devemos considerar $H_{1} \ldots H_{m}$ o conjunto de todas hipóteses nulas testadas e $P_{1} \ldots P_{m}$ seus respectivos $p$-valores e ordenamos os p-valores em ordem crescente denotando-os como $P_{(1)} \ldots P_{(m)}$. A partir daí, definimos uma taxa máxima de erro aceitável $\alpha$ e realizamos os seguintes passos:

1. Encontrar o maior k que satisfaça $P_{(k)} \leq \frac{k}{m} \alpha$

2. Rejeitar a hipótese nula para todos $H_{(i)}$ para $i=1, \ldots, k$

Este teste estatístico é usado no presente trabalho para verificar quais genes apresentam alteração na sua expressão quando comparados a partir de grupos selecionados pelo usuário.

\section{Volcano plot}

Dentre as ferramentas estatísticas gráficas que podemos utilizar para identificar genes diferencialmente expressos está o Volcano plot. 0 volcano plot é um tipo de diagrama de dispersão que tem como principal utilidade apresentar, de forma visual, mudanças que podem ocorrer em grandes conjuntos de dados compostos por experimentos repetidos. Como exemplo de uso podemos citar experimentos de análise de expressão gênica, nos quais existe um elevado número de amostras para cada gene estudado e se deseja saber se existe diferença de expressão entre duas condições de amostra, por exemplo, caso ou controle (CUI, 2003). O volcano plot combina uma medida de significância estatística derivada de um teste estatístico, em geral um p-valor, com uma medida de variação de magnitude. Isso permite uma rápida identificação visual dos genes que têm a variação de expressão gênica ampla e estatisticamente significante. 
O Volcano plot é um gráfico bilogarítmico, no qual o eixo das abscissas representa o log fold change, ou seja, taxa de variação entre o valor máximo e mínimo entre as duas condições observadas, e o eixo das ordenadas representa o logaritmo negativo do pvalor do log fold change, de forma que os pontos localizados na região superior do gráfico são aqueles que apresentam mais alta significância estatística. 0 log fold change é utilizado para que as variações para mais ou para menos da magnitude das observações apareçam equidistantes do centro do gráfico. Desta forma, os pontos de interesse no gráfico são os que estão posicionados mais próximos ao topo e distantes do centro, evidenciando o alto grau de significância estatística e acentuada variação de magnitude. (LI, 2012). A Figura 1 apresenta um exemplo de volcano plot.

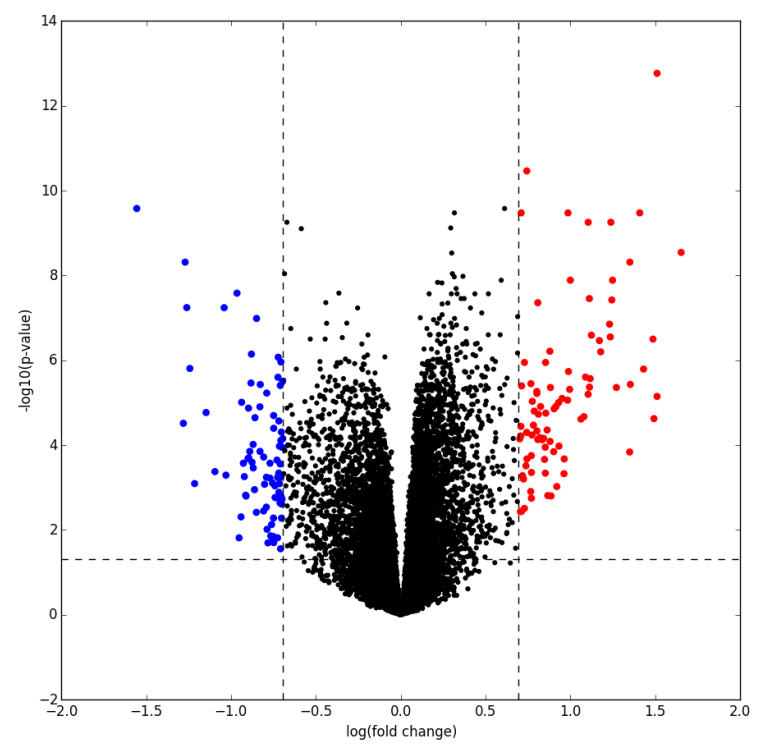

Figura 1 Exemplo de volcano plot de expressão gênica. Pode-se ver os genes sub-expressos em azul e os genes super-expressos em vermelho .

\section{Cluster Heatmap}

O cluster heatmap é uma forma de visualização de dados que revela estruturas de agrupamento hierárquico presentes nas linhas e colunas de uma matriz. Ele consiste em uma matriz, na qual cada elemento é representado por uma cor pertencente a uma escala de cores pré-estabelecida. As linhas ou colunas da matriz são ordenadas de forma que linhas ou colunas similares fiquem próximas umas das outras como mostrado na Figura 2. 

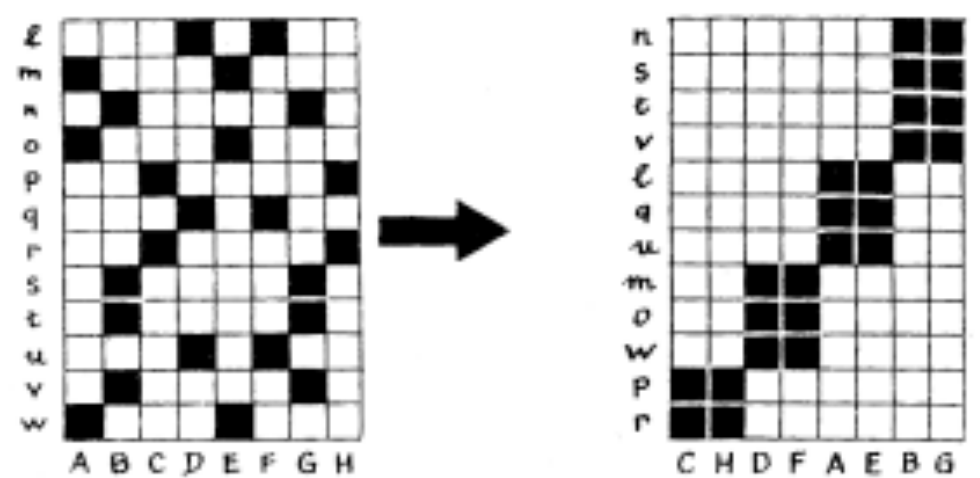

Figura 2 Heatmap sem agrupamento de colunas na esquerda e com agrupamento de colunas por similaridade na direita.

No caso da análise de expressão gênica, as cores associadas aos pontos da matriz indicam o quanto um determinado gene está expresso. Neste caso, as amostras (pacientes) são representadas pelas linhas e os genes pelas colunas. Desta forma, se existirem grupos de amostras cujos valores de expressão gênica variem entrem si, eles serão evidenciados por meio da observação do heatmap como na Figura 3.

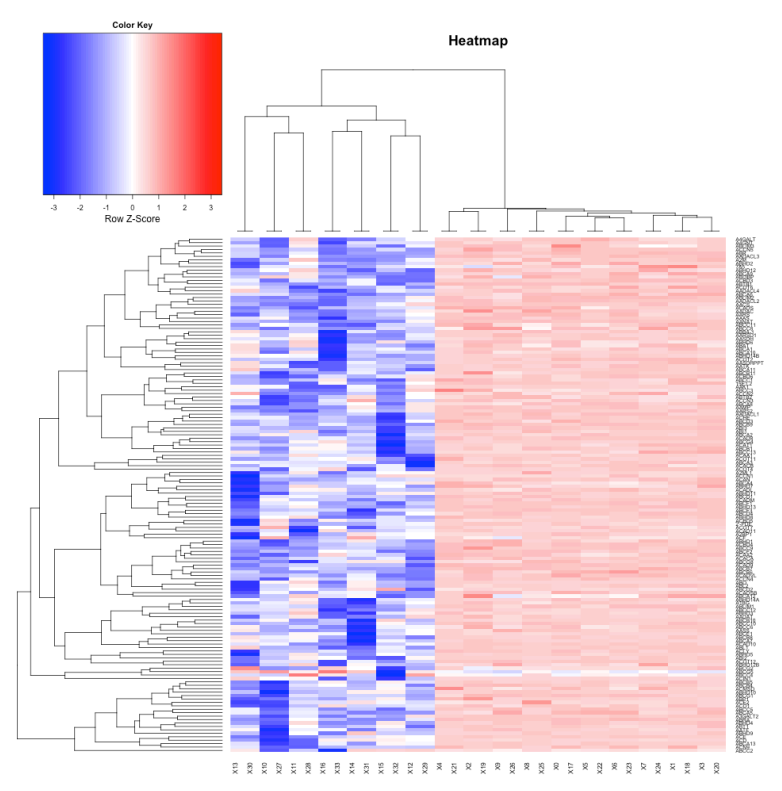

Figura 3 Heatmap de expressão gênica evidenciando a diferença de expressão do grupo de genes selecionados para pacientes controle, na esquerda, versus pacientes com câncer na direita 


\subsection{Mineração de Dados}

Mineração de dados compreende o conjunto de técnicas usadas para auxiliar na descoberta de conhecimento relevante que possa estar presente em uma base de dados. Em geral, estas bases de dados, por serem muito grandes, como data warehouses, por exemplo, não são passíveis de análises por humanos sem auxílio computacional. Desta forma, a mineração de dados pode ser definida como o processo de descoberta de padrões e relacionamentos relevantes dentro de extensos conjuntos de dados (ZHANG, 2002).

Os principais indicadores de que as técnicas de mineração de dados são interessantes de ser aplicadas são:

1. Os padrões a serem identificados não são óbvios ao usuário;

2. A quantidade de dados a serem analisados é proibitivamente grande, impedindo a análise manual.

Podemos classificar a mineração de dados em mineração de dados descritiva e mineração de dados preditiva. A primeira é usada para descrever dados de maneira resumida, apresentando apenas as partes mais interessantes dos dados. Já a mineração de dados preditiva tem como objetivo a construção de modelos preditivos capazes de inferir o comportamento de novas instâncias de dados, baseados em um estudo da base de dados existente.

Outra forma de classificar a mineração de dados é conforme o conhecimento gerado: conhecimento dedutivo, em que é possível deduzir novas informações a partir da aplicação de regras de dedução geradas por meio do conjunto de dados, ou conhecimento indutivo, no qual padrões e associações são identificados a partir do conjunto de dados em análise (ELMASRI, 2011).

Como tarefas ou objetivos da mineração de dados podemos enumerar:

- Associação: descoberta de associações ou correlações entre os itens de um conjunto de dados. Em geral a associação é representada por regras do tipo $X \rightarrow Y$, cujo significado é: quando $X$ ocorre em uma transação $Y$ também ocorre, ou seja, a associação é capaz de estabelecer correlações entre os itens de um conjunto de dados que pertencem a uma mesma transação. 
- Descrição de classes: representação resumida de um conjunto de dados, extraindo suas principais características, capazes de diferenciar um conjunto de dados de outro.

- Predição: processo capaz de predizer valores de dados que estejam indisponíveis ou um intervalo de valores a que este dado possa pertencer, a partir da análise de dados similares a ele. Ou seja, a partir de um conjunto de dados similares, é possível predizer o valor de um dado que esteja indefinido, por exemplo, neste conjunto de dados.

- Agrupamento: processo que permite agrupar itens de um conjunto de dados que possuam similaridade entre si, formando os chamados clusters ou agrupamentos de itens similares. Este processo parte do pressuposto de que ocorra alta similaridade entre os itens pertencentes a um mesmo agrupamento e baixa similaridade entre os agrupamentos diferentes. Isto é, dado um conjunto de dados, o agrupamento é capaz de gerar vários clusters que possuam itens similares, os quais são gerados tipicamente por meio da análise de medidas de distância entre os itens.

- Análise de series temporais: tem como função analisar conjuntos de dados temporais na tentativa de extrair tendências ou regularidades nos dados de acordo com seu comportamento e evolução no tempo, ou seja, a partir de um conjunto de dados temporais, é possível identificar alguns padrões de comportamentos capazes de revelar tendências deste conjunto, possibilitando em alguns casos predizer como será o comportamento dos dados no futuro.

- Classificação: se baseia na geração de modelos capazes de predizer a que classe um certo elemento pertence, a partir de um conjunto de dados de treinamento, ou seja, partindo-se de um conjunto de treinamento, cujas classes de cada elemento são conhecidas, é possível gerar um modelo preditivo capaz de classificar um conjunto novo de dados, atribuindo a cada elemento deste novo conjunto uma classe.

No presente trabalho, a mineração de dados é utilizada a partir de duas de suas tarefas: o agrupamento e a associação. 


\section{Agrupamentos de dados}

Agrupamento pode ser definido como a separação de objetos em classes, tendo como base algum conjunto de atributos cujos valores determinam a similaridade entre os objetos pertencentes ao mesmo grupo, assim como a dissimilaridade entre os objetos pertencentes a grupos distintos (AGRAWAL et al., 2005). Em geral, a similaridade é medida de acordo com métricas de distâncias (euclidiana, manhattan, etc). As técnicas de agrupamento são comumente empregadas em análises estatísticas de dados e amplamente utilizadas no campo da bioinformática.

\section{Consenso de agrupamentos}

Pode-se definir o consenso de agrupamentos como um problema de otimização, no qual deseja-se obter o agrupamento que melhor define um conjunto de dados dentre um conjunto de agrupamentos que tenha sido gerado manualmente ou automaticamente (ABU-JAMOUS et al., 2013). O consenso de agrupamentos fornece ferramentas que facilitam a resolução de problemas clássicos de agrupamento de dados como:

- Torna mais natural o algoritmo de categorização de dados;

- Permite que se trate objetos cujos atributos não podem ser comparados entre si;

- Facilita a determinação do número ótimo de grupos de dados;

- Provê métodos que melhorar a robustez dos resultados do agrupamento por meio da aplicação e análise de diferentes algoritmos de agrupamento.

\section{Regras de Associação}

Dentre as tarefas da mineração de dados, a mineração de regras de associação tem sido utilizada para identificar nas bases de dados relacionamentos que apresentam alta frequência e forte correlação (ZHANG, 2002).

Uma regra de associação pode ser denotada como $X \rightarrow Y(X$ implica em $Y)$, ou seja, a ocorrência de um conjunto de itens (ou valores de atributos) $X$ implica na ocorrência de um conjunto de itens $Y$, em uma mesma transação.

0 conjunto de itens pode ser definido como $I=\left\{i_{1}, i_{2}, \ldots, i_{n}\right\}$ e $A_{i}=v$ é um item, onde $v$ é o valor do item $A_{i}$ em uma relação $R=\left\{A_{1}, A_{2}, \ldots, A_{n}\right\}$. Para definirmos 
formalmente as regras de decisão também precisamos definir o que é itemset: $X$ é um itemset de $I$, se X for um subconjunto de I. 0 conjunto de $A_{i}=v$ é um item da relação $R=\left\{P I D, A_{1}, \ldots, A_{n}\right\}$ onde PID é uma chave. Uma transação $t$ é uma instância de $R$, e uma base de dados transacional $\mathrm{D}$ é definida como um conjunto de transações $\mathrm{t}$ na forma $D=\left\{t_{i}, t_{i+1}, \ldots, t_{n}\right\}$ e $t=\{t i d, t-i t e m s e t\}$.

O exemplo clássico utilizado para demonstrar estas definições é o do supermercado. Neste caso poderíamos considerar todos os produtos disponíveis para venda como $I$, o subconjunto $X$ de produtos e a relação $R$ pode ser representada pela venda de um conjunto de produtos onde cada produto seria um item, o conjunto de produtos comprados seria o itemset e a venda faria o papel da transação $t$. Em outras palavras o cliente tid realizou a compra dos produtos que fazem parte do itemset $X$. Assim, temos que: um itemset poderia ser formado pelos produtos pão, leite e manteiga, sendo cada um desses produtos um item. A compra desses produtos por um cliente poderia ser denotada como uma transação $t=\{1$, leite, pão, manteiga $\}$, onde 1 seria a chave da transação e os items leite, pão e manteiga um itemset dos produtos disponíveis para venda I.

Equivalentemente, podemos dizer que as regras de associação são da forma LHS $\rightarrow$ RHS (Left-hand Side $\rightarrow$ Right-hand Side), ou seja, possuem um lado esquerdo e um lado direito. LHS e RHS representam um item ou um conjunto de itens e LHS U RHS representa um itemset (Elmasri, Navathe 2011).

Destas relações podemos extrair a medida de suporte de um itemset. Um itemset $X$, em uma base de dados transacional $D$, possui suporte denotado por $\operatorname{supp}(X)$, que representa a razão de transações, em $D$, que contém $X$, ou seja:

$$
\operatorname{supp}(X)=\frac{X(t)}{D}
$$

no qual $X(t)=\{t$ em $D \mid t \supset X\}$.

Um itemset $X$ é considerado frequente se tiver suporte maior que um certo suporte mínimo (minsupp) definido por um especialista.

Levando-se em consideração estas definições, podemos definir o suporte de uma regra de associação $X \rightarrow Y$ como sendo o itemset $X$ implica no itemset $Y$, se: $X, Y \subseteq I$ e $X \cap$ $Y=\varnothing$. 
Assim como os itemsets, as regras de associação também possuem uma medida de suporte, além de uma medida de confiança. 0 suporte de uma regra de associação $X \rightarrow$ $Y$ é (ZHANG, 2002):

$$
\operatorname{supp}(X \rightarrow Y)=\operatorname{supp}(X \cup Y)
$$

A confiança da regra $X \rightarrow Y$ é:

$$
\operatorname{conf}(X \rightarrow Y)=\frac{\operatorname{supp}(X \cup Y)}{\operatorname{supp}(X)}
$$

Sendo assim, temos que o suporte significa a frequência com que um certo $X$ ocorre em conjunto com $Y$ na base de dados, e a confiança é a força com que essa ligação ocorre.

A validação das regras de associação, proposta por Agrawal et al (AGRAWAL et al. 1993) pode ser realizada desde que $X \cap Y=\varnothing, \operatorname{supp}(X) \neq 0, \operatorname{supp}(Y) \neq 0$, e que um especialista tenha definido um suporte mínimo (minsupp), e uma confiança mínima (minconf). A regra $X \rightarrow Y$ é válida se:

$$
\begin{aligned}
& \operatorname{supp}(X \cup Y) \geq \text { minsupp }, \\
& \operatorname{conf}(X \rightarrow Y) \geq \text { minconf }
\end{aligned}
$$

Assim, podemos dividir a tarefa de minerar regras de associação em subproblemas menores:

1. Encontrar todos os itemsets que possuam suporte maior ou igual ao suporte mínimo especificado pelo especialista;

2. Gerar todas as regras de associação que possuam confiança maior ou igual a confiança mínima definida pelo especialista, de forma que dado um itemset frequente $X$, e algum $B \subset X$, sendo $A=X-B$. Se o valor de confiança da regra $A \rightarrow B$ é maior ou igual a confiança mínima, então esta regra pode ser considerada válida.

No quadro a seguir é apresentado o algoritmo criado para mineração de regras de associação chamado Apriori, que leva em consideração a metodologia de avaliação do suporte-confiança para extrair as regras válidas. 


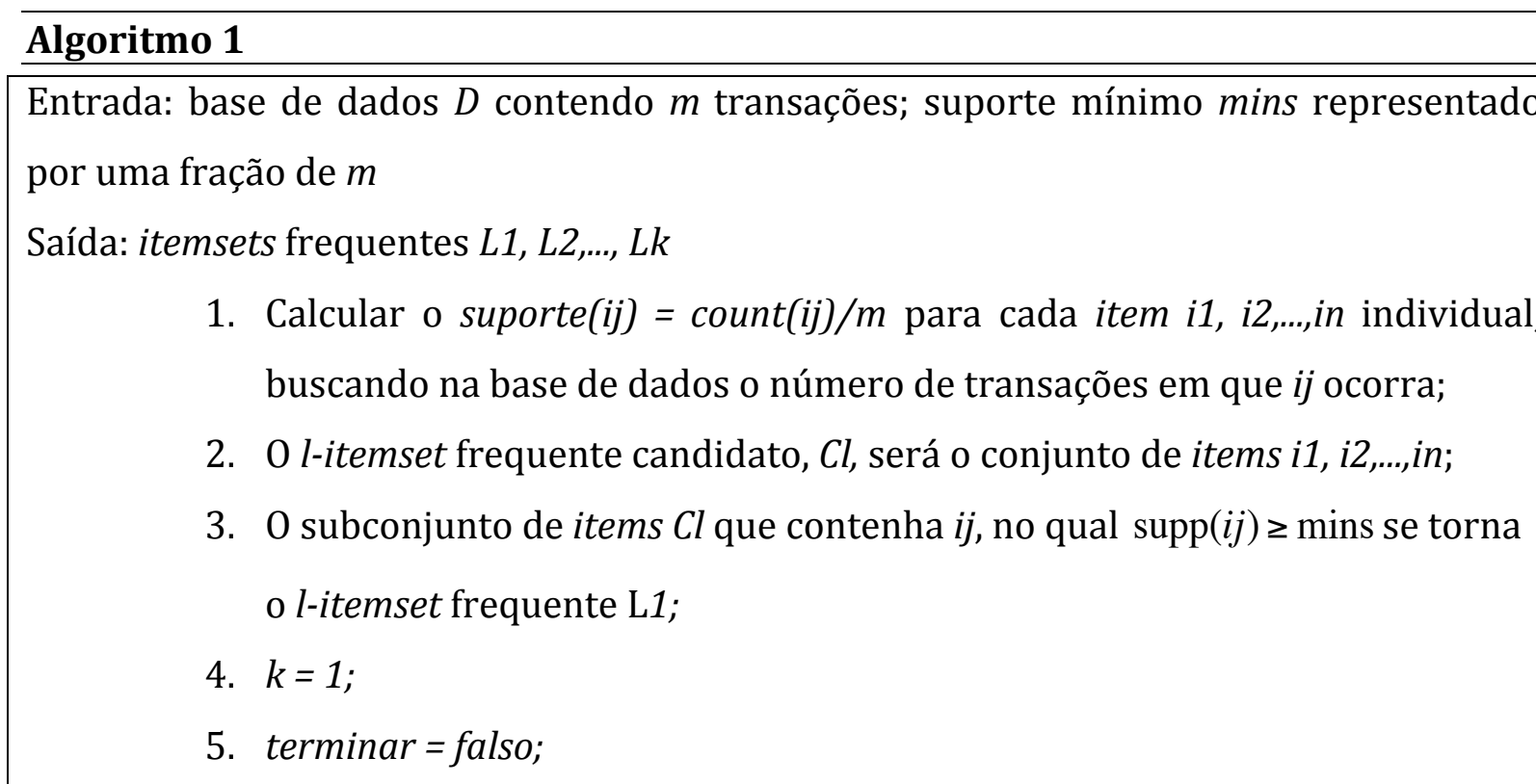

Repita:

1. $L k+1=[]$;

2. Gerar $C k+1$ : $(k+1)$-itemset frequente candidato, adicionando membros de $L k$ que possuam $k$ - 1 items em comum;

3. Adicionalmente, considerar apenas como elementos de $C k+1$ aqueles $k+1$ items, cujos subconjuntos de tamanho $k$ apareçam em $L k$;

4. Percorra a base de dados e calcule o suporte para cada membro de $C k+1$;

Se o suporte do membro $C k+1 \geq \operatorname{mins}$

Então adiciona este membro a $L k+1$

5. Se $L k+1$ for vazio

Então:

1. terminar = verdadeiro;

Senão:

2. $k=k+1$

Enquanto terminar $=$ falso

Na literatura podem ser encontrados outros algoritmos para mineração de regras de associação, no entanto a grande maioria deles consistem de desdobramentos do Apriori. 
No presente trabalho, foi desenvolvida uma funcionalidade da ferramenta IPTrans A2Tool com o objetivo de encontrar associações não evidentes contidas nos dados dos pacientes presentes nas bases de dados analisadas. 0 algoritmo Apriori foi utilizado para mineração de dados baseando-se na criação de regras de associação para encontrar correlações entres dados clínicos e biomoleculares contidos nas bases geridas pelo IPTrans A2Tool. 


\section{Capítulo 3 Trabalhos Correlatos}

Neste capítulo serão apresentados alguns trabalhos relacionados tanto ao IPTrans A2Tool, quanto ao BioBank Warden.

\subsection{Oncomine}

A ferramenta Oncomine (www.oncomine.org/resource/main.html), foi a principal referência de quais ferramentas um sistema robusto de análises deveria fornecer aos pesquisadores. Oncomine é uma base de dados contendo experimentos de microarray relacionados ao câncer, além de prover ferramentas de análise de dados que visam facilitar a descoberta de novos conceitos por meio da análise do genoma. Até o atual momento, Oncomine conta com 715 conjuntos de dados de expressão gênica contendo 86733 amostras. Na Figura 4 é apresentado como as amostras estão distribuídas por subtipo de câncer.

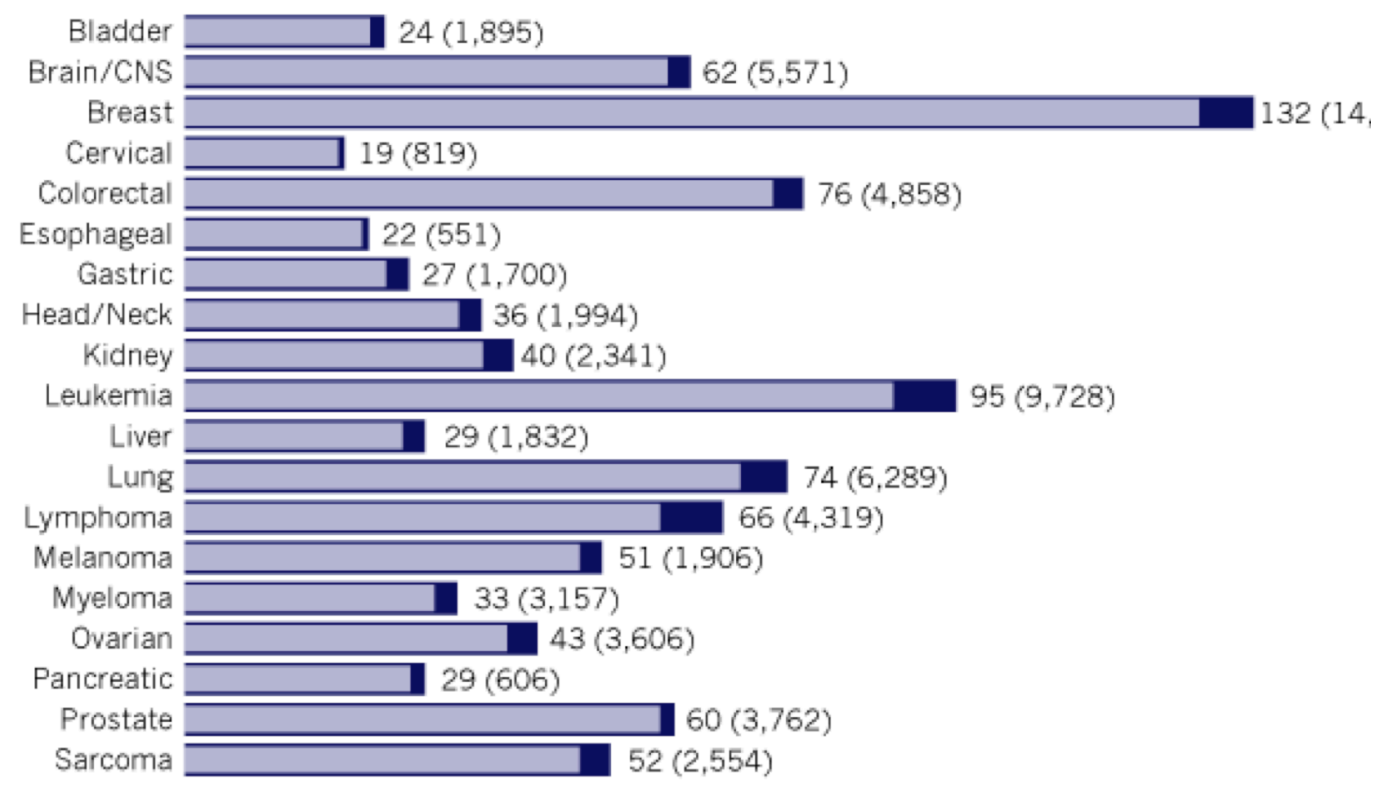

Figura 4 - Distribuição de amostras por subtipo de câncer. A parte mais escura do gráfico representa as novas amostras inseridas na ultima atualização da base de dados. Extraída de: www.oncomine.org/resource/main.html fevereiro de 2014

O sistema permite a busca e visualização de dados de todas as análises pelas quais um gene de interesse foi submetido, ou também pode mostrar dados de todos os genes para uma determinada análise. Entre os tipos de análise que podem ser acessadas está a análise de expressão diferencial, na qual os tipos mais comuns de câncer são 
comparados com os respectivos tecidos normais. Oncomine possui algumas características importantes como (RHODES 2004):

- Módulo GENE - usuários podem visualizar e avaliar análises diferenciais de um gene de interesse em todos os conjuntos de dados disponíveis. Após procurar por um gene de interesse, a ferramenta lista todas as análises diferenciais nas quais o gene foi incluído e permite que o usuário selecione quais análises lhe interessam mais. Para as análises selecionadas, resultados estatísticos são exibidos e ligados às representações gráficas dos dados de microarray.

- Módulo STUDY -disponibiliza um mapa de cores padrão de expressão gênica para que o usuário possa visualizar quais genes têm uma maior variação na expressão gênica dentro de uma dada análise. A maioria das análises contidas no Oncomine são análogas às realizadas nas publicações das quais elas foram extraídas; entretanto, o sistema aplica apenas um método estatístico padrão para todas as análises, mantendo assim a padronização dos resultados. Além disso, algumas análises contidas no Oncomine não foram realizadas em nenhuma publicação, aumentado assim seu valor.

- Integração com a Gene Ontology (GO) - para disponibilizar os potenciais alvos ou marcadores que estão superexpressos, os genes receberam anotações com descritores relevantes da GO.

\subsection{Rembrandt}

Em 2008, visando a integração de dados biomédicos de fontes distintas e devido à falta de consistência na obtenção de dados biomoleculares a partir de um conjunto grande de amostras dificultar o aparecimento de terapias melhores para o tratamento de tumores cerebrais, foi criado pelo National Cancer Insitute (NCI) dos Estados Unidos o Repository of Molecular Brain Neoplasia Data (Rembrandt). Rembrandt é um sistema web que atua como uma base de dados clínicos e genômicos relacionados ao câncer, além de prover funcionalidades de análise dos dados, facilitando assim novas descobertas na área (MADHAVA, 2007). A tabela 2 mostra o número de experimentos armazenados na base de dados Rembrandt. 
Tabela 2 - Números de experimentos armazenados pelo Rembrandt ${ }^{1}$. Última atualização em $27 / 07 / 2010$

\begin{tabular}{|l|l|l|}
\multicolumn{1}{|c|}{ Tipo de dados } & № de participantes no estudo & \multicolumn{2}{|c}{ № de espécimes } \\
\hline Variação de número de cópias & 920 & 552 \\
\hline Expressão gênica & 568 & 577 \\
\hline Dados clínicos & 1018 & 668
\end{tabular}

Dentre as principais características do Rembrandt podemos citar:

- Análises estatísticas avançadas sobre dados genômicos e clínicos Rembrandt suporta tarefas computacionais que demandem alto poderio computacional e capacidade elevada de memória, como comparação entre classes, agrupamentos e Análise de Componentes Principais (PCA). Além disso, múltiplas análises estatísticas podem ser realizadas de forma simultânea. Estas análises são apresentadas por meio de relatórios utilizando gráficos.

- Integração com GenePattern - GenePattern², é uma plataforma de análise genômica que permite o acesso a centenas de ferramentas para análise de expressão gênica, SNP, RNA-seq, além de contar com uma interface web que permite o acesso a essas ferramentas, bem como a pipelines de análise que permitam a reprodutibilidade da pesquisa in-silico. Assim, para prover um número maior de ferramentas aos pesquisadores, Rembrandt possui uma grande integração com a plataforma.

- Análise de número de cópias retirados de amostras de DNA de pacientes versus localização genômica - os usuários podem visualizar gráficos, através de uma aplicação chamada webGenome $^{3}$, que mostram uma comparação entre o número de variantes de número de cópias e a localização física do genoma.

- Interfaces avançadas para pesquisa e relatórios - para exibir ao usuário dados integrados de inúmeros campos de pesquisa, tais como expressão

\footnotetext{
1 https://caintegrator.nci.nih.gov/rembrandt/

2 http://www.broadinstitute.org/cancer/software/genepattern/

3 https://github.com/NCIP/webgenome
} 
gênica, análise do número de cópias e ensaios clínicos, Rembrandt proporciona ferramentas de pesquisa para experimentos de interesse e disponibiliza relatórios contendo todos os dados desejados.

\subsection{Firehose}

Firehose é uma iniciativa do Broad Institute Genome Data Analysis Center (GDAC) ${ }^{4}$ em conjunto com o The Cancer Genome Atlas (TCGA) ${ }^{5}$, para estabelecer pipelines avançados de análise de dados clínicos e biomoleculares com o intuito de acelerar o entendimento do câncer. Este conjunto de ferramentas foi desenvolvido para operar com terabytes de dados de forma eficiente, facilitando pesquisas em larga escala que venham a ser realizadas. A tabela 3 ilustra a quantidade de amostras contidas na base de dados do Firehose.

Tabela 3 - Quantidade de dados por tipo de amostra no Firehose em janeiro de $2014^{6}$

\begin{tabular}{|l|l|}
\multicolumn{1}{|c|}{ Tipo de Amostra } & \multicolumn{2}{c|}{ № de amostra } \\
\hline BCR & 9483 \\
\hline Clinicas & 7593 \\
\hline CN & 8487 \\
\hline LowP & 1091 \\
\hline MAF & 5335 \\
\hline miRSeq & 7470 \\
\hline miRNASeq & 7478 \\
\hline
\end{tabular}

Dentre as ferramentas do Firehose podemos listar:

- $\quad$ Processamento de microarray - pode ocorrer em três níveis: nível 1, dados brutos; nível 2, dados das probes e nível 3, dados de genes, ou seja, dados relacionados à expressão de mRNA e miRNA.

\footnotetext{
${ }^{4}$ http://www.broadinstitute.org/

${ }^{5}$ http://cancergenome.nih.gov/

${ }^{6}$ https://confluence.broadinstitute.org/display/GDAC/Standardized+Data+Run+Release+Notes
} 
- Pipeline para dados clínicos - podem ser feitas análises sobre dados clínicos, como correlacionar algumas características clínicas com a alteração de dados biomoleculares.

- Pipelines de análises gerais -análises podem ser feitas de acordo com os dados biomoleculares que estão sendo estudados através de pipelines para: RNAseq, miRSeq, mRNA, metilação, mutações, variantes de número de cópia, vias metabólicas e para controle de qualidade.

No capítulo 4 os principais recursos destas ferramentas serão comparados com aqueles disponibilizados pela ferramenta IPTrans A2Tool.

\subsection{IPTrans (Integrative Platform for Translational Research)}

O IPTrans (Integrative Platform for Translational Research), projetado e implementado em um trabalho anterior (MYIOSHI, 2013), consiste em um framework de integração de dados obtidos em estudos de medicina translacional (estudos clínicos, genômicos e sócio-demográficos), provenientes de múltiplas fontes, que utiliza uma ontologia de referência para realizar o mapeamento entre os atributos de cada base de dados. 0 framework apresenta uma arquitetura composta por quatro níveis: nível de dados, responsável pelo armazenamento dos dados; nível semântico, responsável pela integração e padronização dos dados por meio do uso de ontologias; nível de aplicação, responsável por gerir as bases de dados clínicos, ontologias de referencia e os processos de integração; nível de interface web, que permite a interação entre o usuário e o sistema (MYIOSHI et al., 2013).

\subsubsection{Arquitetura do IPTrans}

Para poder integrar dados de estudos de medicina translacional oriundos de diferentes fontes, o IPTrans utiliza um modelo de banco de dados relacional, modular e baseado em ontologias, criado para representar dados biológicos, denominado Chado (MUNGALL, 2007). Chado oferece uma plataforma genérica que pode ser utilizada como base para diferentes tipos de pesquisa genômica, sendo parte do GMOD (Generic Model Organism Database). A arquitetura do Chado compreende dezoito módulos, cada qual composto por um conjunto de tabelas, gatilhos e funções responsáveis por gerenciar 
dados de um subdomínio da genômica. Um dos motivos que levaram à escolha do Chado como facilitador da integração dos dados é sua extensibilidade, ou seja, ele permite que novos módulos sejam criados, ou que os atuais sejam modificados caso necessário. Outra importante característica do Chado é que ele utiliza ontologias ou outras formas de vocabulários controlados para relacionar e agregar seus dados.

Desta forma, o IPTrans consistiu na implementação de um novo módulo do Chado, o módulo clínico, responsável por armazenar e representar informações clínicas de bases de dados legadas, uma vez que o Chado suportava apenas informações biomoleculares. 0 módulo clínico foi implementado utilizando um modelo EntidadeAtributo-Valor (EAV). No modelo EAV, os dados são representados por uma tupla composta por três itens:

1. Entidade: o identificador do item ou indivíduo que está sendo descrito;

2. Atributo: a descrição de um atributo pertencente ao item;

3. Valor: o valor do atributo para o determinado indivíduo.

O modelo EAV é aplicado quando o os dados são esparsos, altamente heterogêneos, com um amplo número de atributos e quando a inserção de novos atributos é frequente, como no caso do IPTrans A2Tool.

As tabelas do módulo clínico suportam diferentes tipos de dados, como: dados sócio-demográficos (idade, sexo, peso, local de moradia), e dados clínicos (tipo do tumor, tratamento, sintomas e etc).

\subsubsection{Níveis do sistema}

A seguir serão apresentados os níveis que constituem o IPTrans: nível de dados, nível semântico, nível de aplicação e nível de interface web.

\section{Nível de dados}

O nível de dados é responsável por armazenar os dados. É composto por um sistema gerenciador de banco de dados no qual reside a implementação do modelo de dados do Chado. É neste nível que está implementado o módulo de dados clínicos e suas respectivas tabelas. 


\section{Nível semântico}

O nível semântico é composto por um conjunto de modelos de bancos de dados e ontologias. Ontologias podem compreender tesauros, vocabulários controlados, terminologias, modelos de informação e ontologias formalmente definidas (VIDAL, 2009). Podemos classificar os modelos armazenados no nível semântico de três formas:

- Modelo de base de dados: descrevem a estrutura da base de dados clínicos. Necessita que a estrutura de dados (tabelas e suas colunas), sejam descritas de forma precisa.

- Ontologias de domínio: são ontologias que representam conceitos de um domínio especifico como: SNOMED, Gene Ontology e etc.

- Ontologia de referencia: é a ontologia responsável por integrar e mapear as bases de dados clínicas. Pode ser composta por uma ou mais ontologias de domínio.

\section{Nível de aplicação}

É o nível composto por uma série de módulos e métodos responsáveis por gerenciar, criar, atualizar e recuperar toda a informação contida no IPTrans.

\section{Nível de interface web}

Neste nível está implementado um conjunto de interfaces web, que permitem que o usuário insira novos dados, selecione a ontologia de referencia e realize algumas consultas simples na base de dados do IPTrans. 


\section{Capítulo 4 Proposta do Framework de Análise}

\subsection{Considerações iniciais}

Neste capítulo serão descritas as ferramentas desenvolvidas ao longo deste trabalho. Primeiramente, será apresentado o framework de análise de dados proposto neste projeto, o IPTrans A2Tool e, em seguida, o sistema de gerenciamento de dados clínicos e biomoleculares, denominado Biobank Warden.

\subsection{Ferramenta IPTrans A2Tool}

A ferramenta IPTrans A2Tool tem como objetivo oferecer aos seus usuários, pesquisadores da área de genética, recursos que permitam facilitar o trabalho de análise dos dados gênicos, oferecendo recursos para relacionar os dados biomoleculares com dados clínicos e fenotípicos de pacientes, assim como recursos de mineração de dados. 0 IPTrans A2Tool agrupa algumas funcionalidades já presentes nas ferramentas Oncomine, REMBRANDT e Firehose, além de também disponibilizar funções inexistentes nestas ferramentas estudadas, mas que são importantes para o desenvolvimento de pesquisas na área da medicina translacional.

É importante ressaltar que os dados que são utilizados pela ferramenta IPTrans A2Tool já devem estar previamente normalizados. Para isso foi convencionado que as bases de dados apresentem seus dados normalizados de acordo com o nível 3 de normalização fornecido pelo TCGA7 .

\subsubsection{Arquitetura da ferramenta IPTrans A2Tool}

O IPTrans A2Tool é um sistema estruturado a partir de um modelo multicamadas, nas quais estão implementados módulos responsáveis por implementar todas as funcionalidades do sistema. As camadas que compõe o IPTrans A2Tool serão descritas com mais detalhes a seguir.

\footnotetext{
${ }^{7}$ https://wiki.nci.nih.gov/display/TCGA/Data+level
} 


\section{Camada de dados:}

A camada de dados é subdividida em duas partes: o framework IPTrans e o sistema gerenciador de bancos de dados que armazena os resultados das análises. 0 papel do framework IPTrans é armazenar, integrar e prover mecanismos de recuperação dos dados clínicos e biomoleculares armazenados no mesmo, para que possam ser disponibilizados para as análises realizadas pelos usuários do sistema. 0 sistema gerenciador de bancos de dados é responsável por armazenar algumas informações provenientes das análises para que possam ser exibidas para o usuário.

\section{Camada de aplicação:}

Nesta camada estão presentes todos os módulos e métodos encarregados de analisar os dados e gerar os resultados para o usuário. Dentre seus componentes estão algoritmos que implementam as análises estatísticas como teste-t de Welch, outros que geram as matrizes e criam as imagens dos heatmaps e volcano plots. Também existe um módulo especializado em organizar os dados clínicos e biomoleculares para aplicar o algoritmo A priori de mineração de regras de associação de dados.

\section{Camada de interface do usuário:}

Na camada de interface do usuário estão todas a interfaces e métodos responsáveis pela interação do usuário com o sistema e exibição dos dados provenientes das análises.

A figura a seguir ilustra as camadas que compõem o IPTrans A2Tool

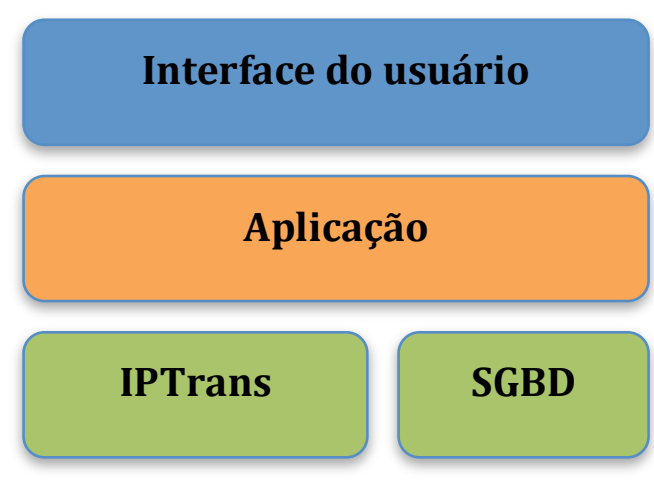

Figura 5 Arquitetura multicamadas do sistema IPTrans A2Tool. 


\subsubsection{Funcionalidades do IPTrans A2Tool}

As funcionalidades do IPTrans A2Tool serão apresentadas a seguir como os requisitos funcionais do sistema. Em seguida, será apresentada uma tabela comparativa das funcionalidades do sistema com as apresentadas pelos trabalhos correlatos.

\section{Requisitos funcionais}

\section{Visualização dos dados:}

A ferramenta IPTrans A2Tool disponibiliza ao usuário algumas formas de visualização dos dados como heatmaps, volcano plots e consenso de agrupamentos. Também conta uma interface amigável, proporcionando ao usuário uma experiência mais fácil na realização e visualização de suas análises.

\section{Seleção dos dados:}

Para que o pesquisador possa selecionar os dados mais relevantes para sua pesquisa, a ferramenta proposta conta com métodos de seleção de dados que levem em conta dados clínicos, biomoleculares, sócio-demográficos, tipo de experimento e ensaio clínico ao qual o experimento pertence. Isto permite que o usuário tenha um maior controle sobre quais dados serão analisados, evitando vieses causados por dados indesejados.

\section{Análise diferencial de níveis de expressão gênica:}

Uma das funcionalidades implementada pela ferramenta IPTrans A2Tool é a análise diferencial de níveis de expressão gênica. Esse tipo de análise é usado para avaliar a diferença nos níveis de expressão gênica entre dois ou mais genes, ou entre diferentes experimentos feitos com um mesmo gene. Normalmente, para realizar este tipo de análise, um conjunto de amostras é selecionado e, a partir da seleção, é gerado um heatmap por meio do qual o usuário pode visualizar a diferença nos níveis de expressão gênica. Esta análise é uma funcionalidade importante, que permite que as amostras sejam confrontadas rotulando-as da seguinte forma:

- Normal versus câncer (caso versus controle);

- Câncer versus câncer (dois diferentes tipos de câncer sejam confrontados);

- Normal versus normal (apenas amostras de pacientes controle sejam confrontadas). 
O IPTrans A2Tool incrementa este tipo de análise integrando-a com dados clínicos, ou seja, o usuário pode selecionar os grupos de amostra a partir de suas características clínicas, tais como sexo, raça, idade, histórico familiar e diagnóstico, entre outras, podendo, assim, encontrar fatores clínicos que evidenciem ou sejam decorrentes da variação de expressão em determinados genes.

\section{Associação de dados clínicos e biomoleculares:}

É interessante que variações de expressão gênica possam ser associadas, quando possível, a alguma característica clinica (ou um conjunto delas) que demonstre a ocorrência desta mutação. Para tanto podemos usar técnicas e algoritmos de mineração de dados, como o algoritmo para criar regras de associação que possam levar o pesquisador a obter a probabilidade e fator de confiança com que determinados dados clínicos e biomoleculares possam estar associados. Assim, devido ao poder de abstração de regras do algoritmo, o pesquisador poderia encontrar relações entre os dados que seriam difíceis ou impossíveis de serem inferidas manualmente.

Na Tabela 4 é apresentada uma comparação entre as funcionalidades propostas para o IPTrans A2Tool e as ferramentas apresentadas como trabalhos correlatos no capítulo 3.

Tabela 4 - Comparativo de funcionalidades entre o IPTrans A2Tool e as ferramentas estudadas.

\begin{tabular}{|l|c|c|c|c|}
\hline & Oncomine & REMBRANDT & Firehose & IPTrans A2Tool \\
\hline $\begin{array}{l}\text { Visualização dos } \\
\text { dados }\end{array}$ & $\operatorname{sim}$ & $\operatorname{sim}$ & $\operatorname{sim}$ & Sim \\
\hline Seleçăio dos dados & $\operatorname{sim}$ & $\operatorname{sim}$ & $\operatorname{sim}$ & Sim \\
\hline Análise diferencial & $\operatorname{sim}$ & não & não & sim (integrada) \\
\hline $\begin{array}{l}\text { Associaçăo dos } \\
\text { dados }\end{array}$ & não & não & $\operatorname{sim}$ & Sim \\
\hline
\end{tabular}

Como pode-se observar na Tabela 4, o IPTrans A2Tool conta com as funcionalidades mais importantes presentes nos trabalhos correlatos. No entanto seu diferencial está no fato que ele foi construído para servir a usuários com pouca experiência no pipeline de análise de dados de expressão gênica de microarray. Isto 
permite que um número maior de usuários possa ter acesso aos dados providos pelo framework IPTrans, além de oferecer ferramentas importantes para análise de expressão gênica diferencial.

\section{Requisitos não funcionais}

\section{Usabilidade:}

A ferramenta de análise IPTrans A2Tool deve prover métodos de análise que facilitem o processo de pesquisa de pesquisadores na área de bioinformática que não possuam conhecimento profundo em computação, programação, estatística ou ferramentas complexas de análises de dados. Para tanto, a interface deve ser clara, simples e intuitiva.

\section{Desempenho:}

Tendo em vista o grande volume de dados obtidos em experimentos de microarray, o IPTrans A2Tool precisa contar com otimizações para manipular os dados e realizar as análises de forma ágil.

\subsubsection{Casos de Uso do IPTrans A2Tool}

A seguir serão apresentados os diagramas de caso de uso do IPTrans A2Tool. Cada diagrama representa um fluxo de ações tomadas pelo usuário com o intuito de obter uma determinada resposta do sistema.

Todos os casos de uso têm em comum a fato de que, primeiro, o usuário deve selecionar uma ou mais bases de dados contidas e integradas pelo IPTrans. De acordo com sua seleção o sistema automaticamente mapeia os atributos comuns entre as bases de dados e permite que o usuário aplique filtros contendo um ou uma combinação destes atributos. Após aplicado o filtro, internamente, o sistema irá gerar dois grupos de amostras: o grupo que passa na filtragem realizada pelo usuário, e o grupo que não passa na filtragem. Estes grupos terão seus dados confrontados para que seja realizada a análise de expressão diferencial. Também em comum está a criação de uma tabela contendo dados para cada gene analisado como valores de expressão média e p-valor ajustados que pode ser utilizada para validação das análises.

O primeiro caso de uso demonstra as ações tomadas pelo usuário para obter um heatmap de expressão gênica diferencial. Como dito, o usuário deve realizar a etapa 
comum de seleção de dados, selecionar quantidade de genes que serão exibidos no heatmap e disparar o início da análise. É gerada a tabela comum de dados de expressão obtida pela análise e a figura contendo o heatmap de expressão gênica diferencial, sendo possível fazer o download da mesma. A Figura 6 exibe o diagrama de caso de uso para gerar o heatmap de expressão gênica diferencial.

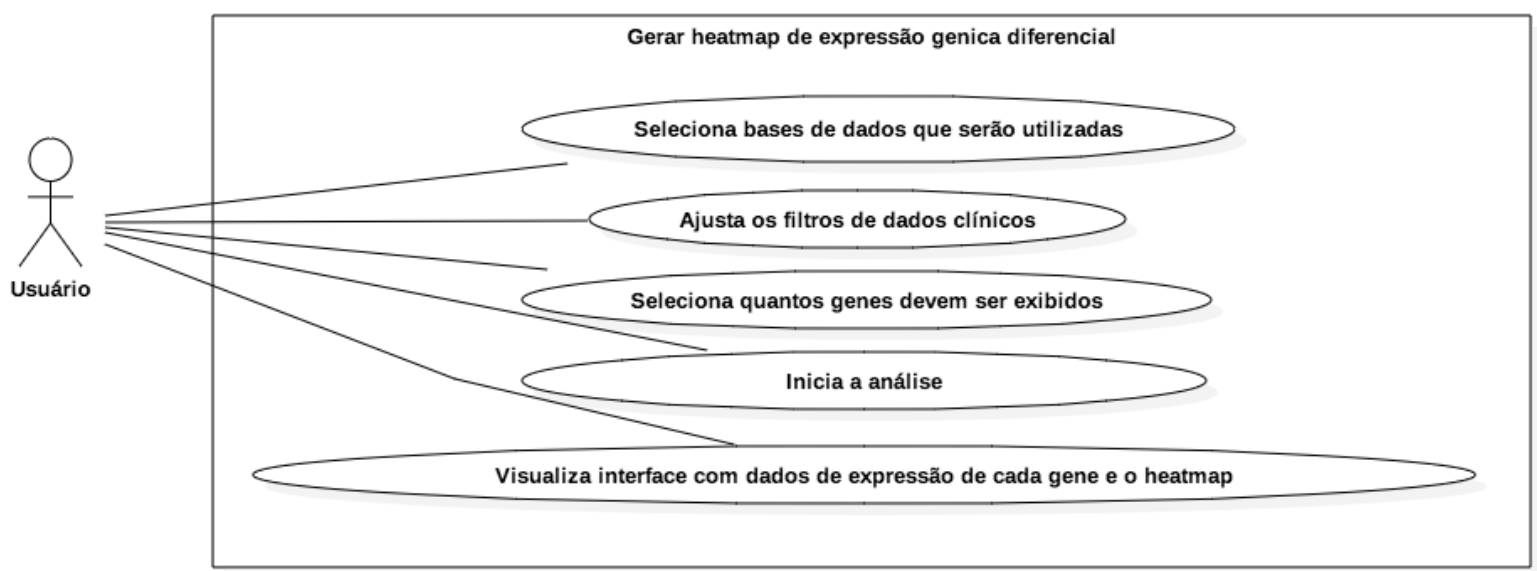

Figura 6 Caso de uso para obtenção de heatmap de expressão diferencial.

O segundo caso de uso demonstra os passos tomados pelo usuário para gerar um volcano plot para avaliação dos genes que apresentem uma significativa variabilidade de expressão gênica entre os dois grupos confrontados. Como em todos os casos de uso, o usuário seleciona as bases de dados e gera os grupos a serem analisados. Em seguida, ele deve selecionar o p-valor de referência e o fold-change utilizados nos eixos do volcano plot e finalmente iniciar a análise. Como resultado da análise, é exibida a tabela contendo os dados de expressão gênica e a figura com o volcano plot gerado com os dados de expressão gênica dos grupos selecionados. A Figura 7 exibe o diagrama de caso de uso para geração do volcano plot.

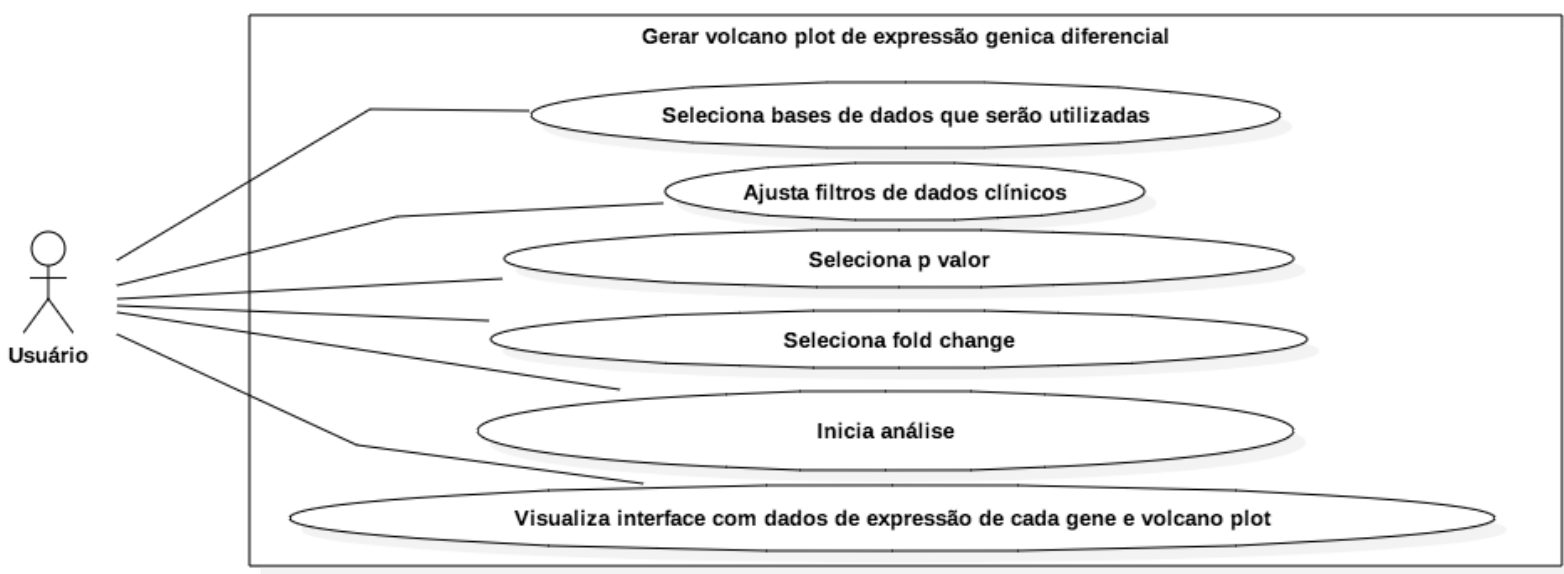


Figura 7 Caso de uso exemplificando os passos realizados para gerar um volcano plot de expressão gênica diferencial.

O próximo caso de uso ilustra os passos necessários para que seja gerado um conjunto de figuras e gráficos utilizados para a seleção do melhor número de agrupamentos que define os dados. Como nos casos anteriores, o usuário seleciona as bases de dados e filtra as amostras. Em seguida ele define o número máximo de grupos que o conjunto de dados pode apresentar e dispara o início da análise. Como resultado o usuário irá encontrar a tabela de dados de expressão gênica e um conjunto de imagens contendo gráficos e matrizes que ajudarão o usuário a definir em quantos grupos distintos (além dos dois já gerados pelos filtros), o conjunto de dados pode ser subdividido. A Figura 8 mostra o diagrama de caso de uso para a geração do agrupamento consenso dos dados.

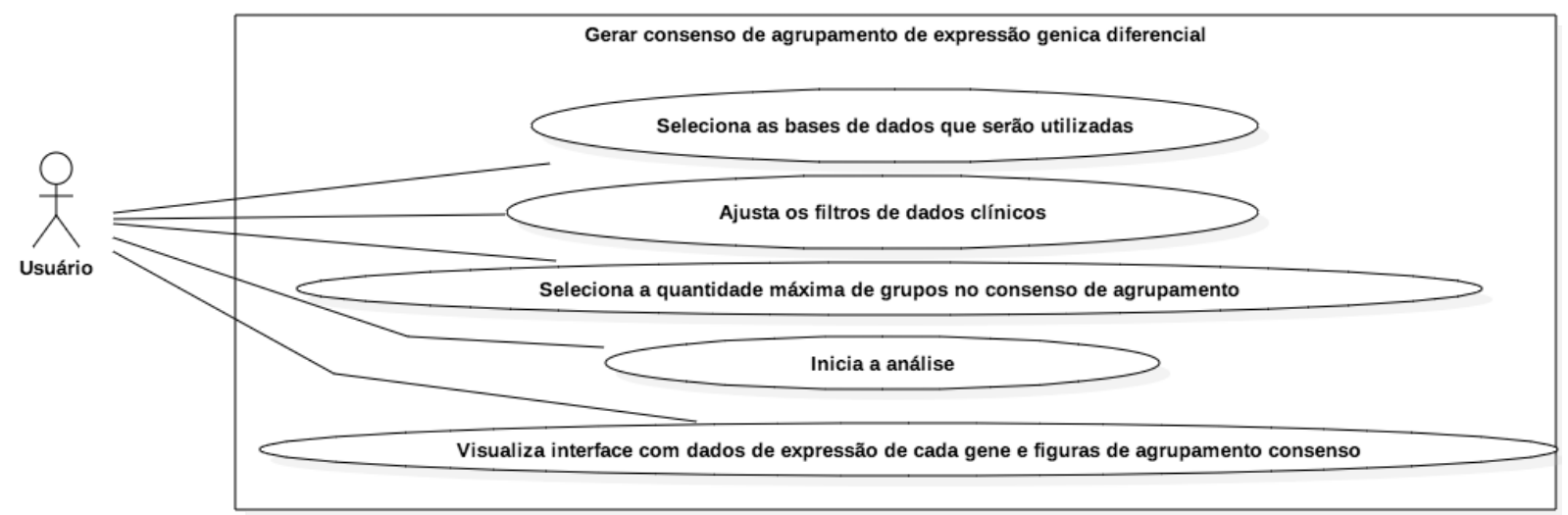

Figura 8 Figura exibindo o diagrama de caso de uso para obtenção de gráficos de agrupamento consenso.

O caso de uso final descreve o processo de geração de regras de associação entre dados clínicos e biomoleculares. Ele difere dos demais casos de uso, pois nele as etapas de de seleção das bases e exibição dos atributos são as mesmas, no entanto, os atributos selecionados serão os que pderão compor as regras de associação geradas. Após a seleção dos dados o usuário deve indicar os valores de suporte e confiança que o algoritmo de mineração de dados a priori irá utilizar, e finalmente deverá iniciar a análise. Como resultado o sistema apresentará uma lista de regras de associação com seus respectivos valores de suporte e confiança, caso sejam encontradas. A Figura 9 ilustra o diagrama de caso de uso para mineração de regras de associação entre dados clínicos e biomoleculares. 


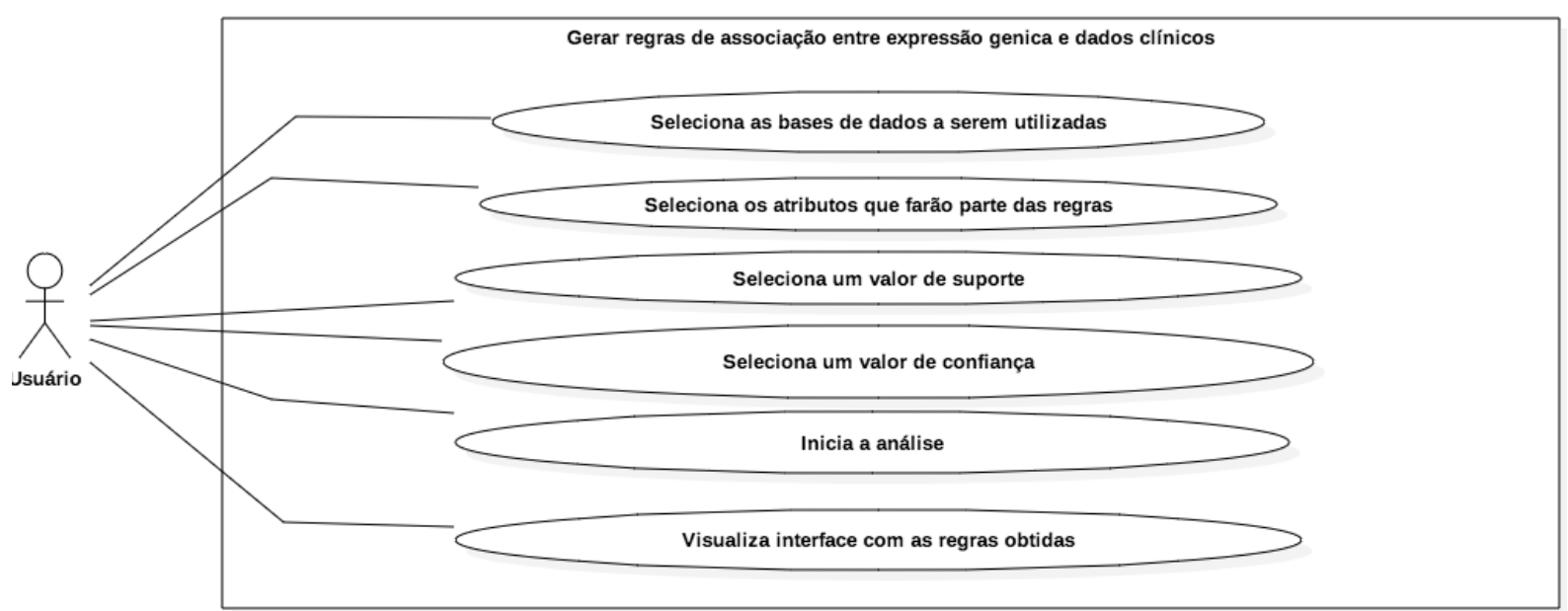

Figura 9 Figura ilustrando o diagrama de caso de uso para mineração de regras de associação entre dados clínicos e biomoleculares.

\subsubsection{Diagrama Entidade Relacionamento IPTrans A2Tool}

Nesta seção será descrito o diagrama entidade relacionamento (DER) do IPTrans A2Tool. Este diagrama apresenta as tabelas contidas no sistema gerenciador de bancos de dados utilizados pelo sistema e cada tabela terá sua função apresentada. A Figura 10 mostra o DER do IPTrans A2Tool.

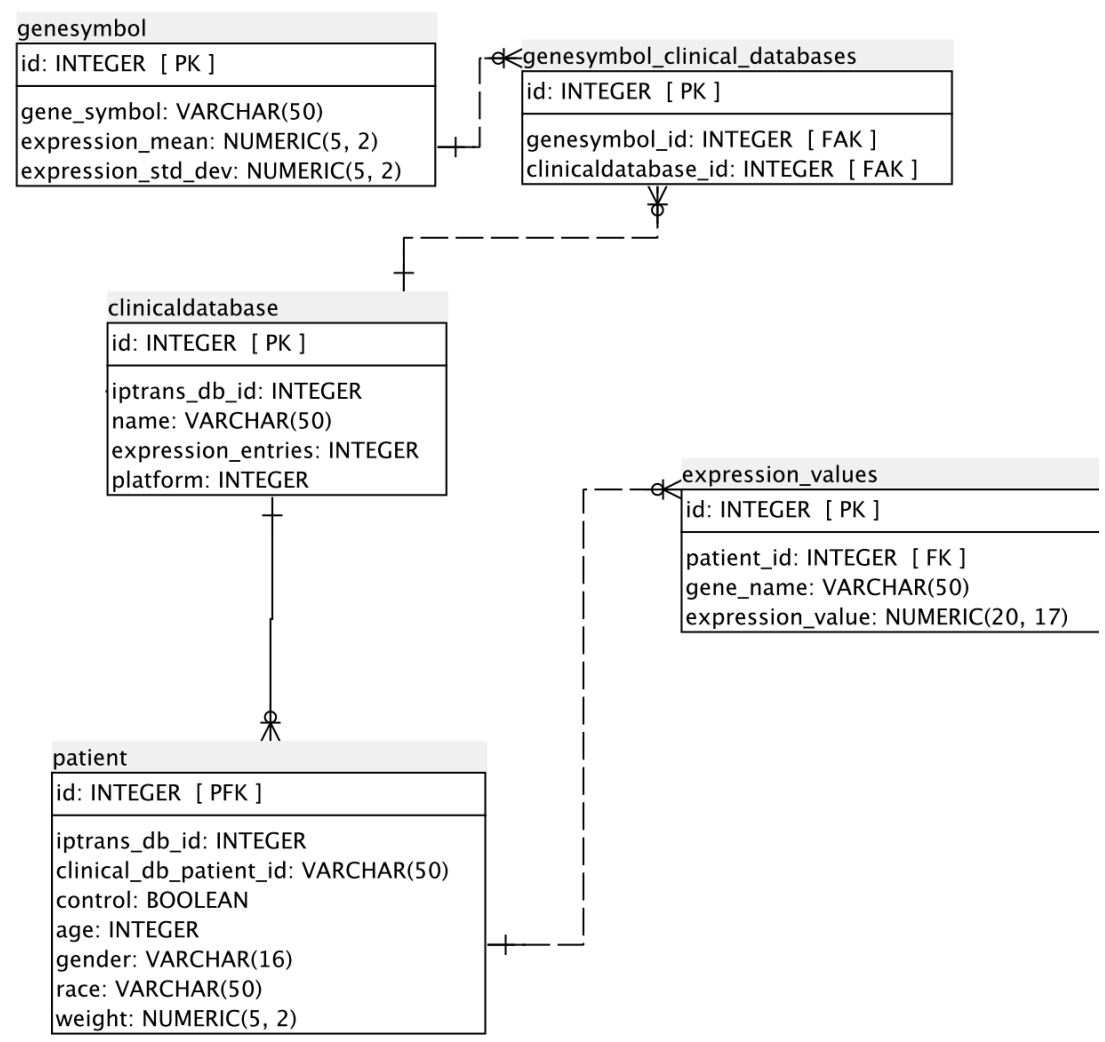

Figura 10 DER do IPTrans A2Tool 


\section{Tabela Patient}

Esta tabela é responsável por armazenar dados temporários básicos dos pacientes selecionados para realizar as análises oferecidas pelo sistema.

\section{Tabela expression_values}

Tabela responsável por armazenar temporariamente os dados de expressão gênica de um determinado gene, para um paciente (amostra) específico.

\section{Tabela clinicaldatabase}

Tabela que representa uma base de dados clínica contida no sistema IPTrans. Esta tabela é necessária para armazenar informações de quantidade de medidas de expressão gênica, nome da base de dados e plataforma de microarray utilizada.

\section{Tabela genesymbol}

Tabela que representa um gene e seus valores de expressão médios em uma determinada base de dados.

\section{Tabela genesymbol_clinical_databases}

Tabela utilizada para mapear o relacionamento $\mathrm{M}$ para $\mathrm{N}$ entre as tabelas clinicaldatabase e genesymbol.

\subsection{BioBankWarden}

O BioBank Warden é um sistema de informação web que visa gerenciar dados clínicos e biomolecures provenientes de pesquisas. É construído com tecnologia Web 2.0, permitindo assim prototipação rápida, interface flexível e gerenciamento de dados robusto.

\subsubsection{Requisitos funcionais}

Dentre os requisitos funcionais do sistema levantados com os pesquisadores e futuros usuários estão: 


\section{Gerenciamento de materiais biológicos}

O BioBank Warden tem como uma de suas principais funções o gerenciamento de materiais biológicos. Esta função se baseia na inserção e retirada de quantidades desses materiais, com controle automático de estoques, bem como no controle de quem as realiza. Para isto, o sistema conta com um controle estrito de permissões de acesso aos materiais biológicos, garantindo assim que só usuários específicos tenham acesso aos mesmos. Além disso, o BioBank Warden permite aos usuários definir a localização física de onde o material está ou será armazenado, facilitando sua disponibilização.

\section{Gerenciamento de dados clínicos}

Cada material biológico armazenado no BioBank Warden está relacionado a um paciente que pode possuir dados referentes a diversas especialidades clínicas que utilizem o BioBank Warden para armazenar seus dados de biomateriais. Assim o sistema possibilita a inserção de informações do paciente, tais como informações gerais de identificação e residência, dados clínicos laboratoriais, anatomopatológicos, acompanhamentos realizados e exames de imagem, todos específicos para cada especialidade encontrada no sistema. Estas informações só podem ser visualizadas por usuários que apresentem determinados níveis de permissão para manter o cunho ético, o sigilo dos dados dos pacientes e a restrição de acesso a projetos específicos.

\section{Gerenciamento de grupos e papéis de usuários}

O BioBank Warden permite que seus usuários façam parte de dois tipos de grupo, com diferentes papéis:

- Grupos de coleta de material biológico - estes grupos são específicos para cada tipo de câncer que venha ter materiais biológicos armazenados no BioBank Warden. Cada grupo deve se responsabiliza pela inserção tanto dos dados dos pacientes dos quais foram extraídas as amostras, quanto dos dados das amostras retiradas dos mesmos pacientes. Os grupos podem ter tipos de participantes organizados hierarquicamente, como coordenador, pesquisador, 
pesquisador clínico e técnico, onde cada tipo de usuário tem acesso à determinadas funções do sistema.

- Projetos de pesquisa - Os coordenadores dos grupos de coleta de material biológico podem criar grupos de projeto de pesquisa ligados aos grupos os quais coordenam. A função destes projetos de pesquisa é permitir que seus participantes tenham acesso aos dados de paciente e materiais biológicos de forma controlada. Além disso, é possível que os participantes do grupo requisitem amostras de biomateriais armazenados no BioBank Warden para suas pesquisas. Assim como nos grupos de coleta de materiais biológicos, os usuários dos grupos de pesquisa também são organizados hierarquicamente em coordenador, pesquisador e estudante, os quais possuem diferentes níveis de acesso dentro do sistema.

Por meio desta separação em diferentes tipos de grupos, onde cada papel possui diferentes níveis de acesso, pode ser realizado o controle dos usuários que acessam o sistema, garantindo uma maior segurança e confidencialidade com os dados.

\subsubsection{Requisitos não funcionais}

Os requisitos não funcionais levantados para o desenvolvimento do sistema foram:

\section{Desempenho}

O BioBank Warden precisa ser um sistema ágil, que permita a inserção de dados de forma rápida e eficiente. Para isso o sistema foi implementado usando um framework da linguagem Python, cujos módulos principais são escritos na linguagem $\mathrm{C}$, muito conhecida por seu desempenho otimizado.

\section{Usabilidade}

Umas das maiores preocupações durante o desenvolvimento do BioBank Warden foi a construção de uma interface de usuário limpa, amigável ao usuário e autoexplicativa. Para isto, durante todo o ciclo de desenvolvimento foram apresentados 
aos futuros usuários as interfaces do sistema e foram colhidas opiniões a respeito da sua facilidade de uso e também opiniões estéticas.

\section{Confiabilidade}

Devido à importância dos dados armazenados pelo BioBank Warden, foi necessária um grande foco em confiabilidade e robustez do sistema. Para isso o sistema conta com rotinas de validação de dados de entrada e também de dados armazenados. Além disso, devido ao elevado número de dados armazenados pelo sistema, foi escolhido o SGBD PostgreSQL, considerado um dos mais confiáveis existentes.

\subsubsection{Casos de uso BioBank Warden}

A seguir serão descritos os diagramas de caso de uso para as principais funcionalidades do BioBank Warden. Cada diagrama representa um fluxo de ações tomadas pelo usuário com o intuito de obter uma determinada resposta do sistema.

O diagrama de casa de uso a seguir descreve como um usuário do BioBank Warden deve proceder para acessar as seções privadas do sistema. Para isso ele deve acessar a página web do sistema. Em seguida, ele deve fornecer suas credencias de acesso, ou seja, usuário e senha para que o sistema possa verificar se o usuário, de fato, possui acesso ao BioBank Warden. Finalmente, após suas credenciais serem validadas positivamente, o usuário é redirecionado para a parte privada do sistema. A Figura 11 mostra o diagrama de caso de uso descrito acima.

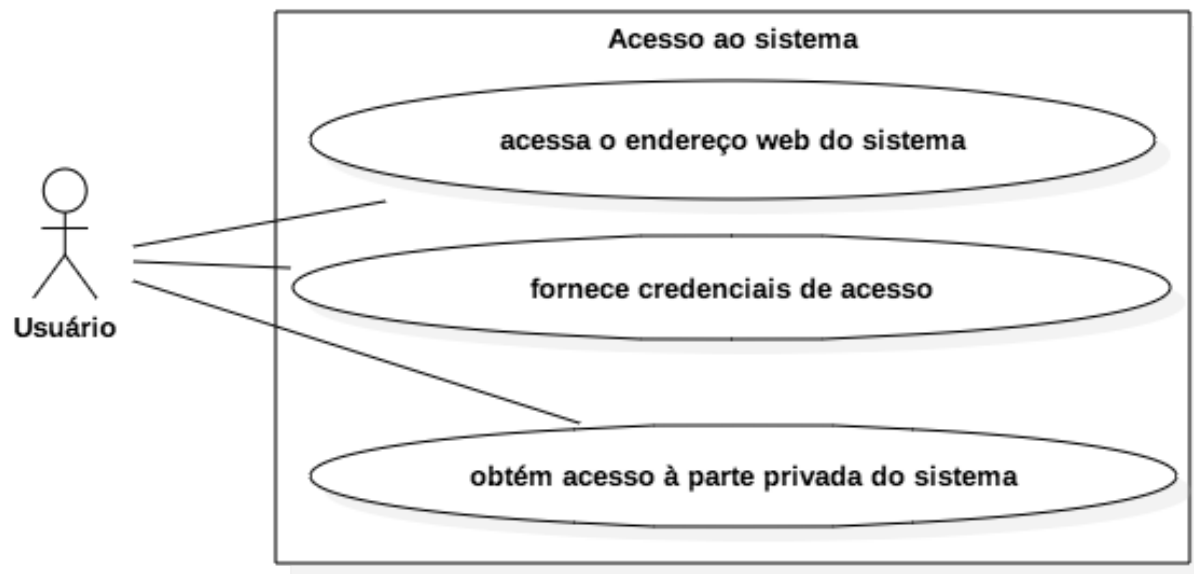

Figura 11 Diagrama de caso de uso para acesso as seções privadas do sistema. 
Para a inserção de um novo paciente no sistema, é necessário que o usuário acesse a guia pacientes e a partir daí será exibida a opção de adicionar novo paciente. Após o usuário selecionar esta opção, será exibida para ele uma interface contendo um formulário para que os dados básicos de identificação do paciente sejam inseridos. 0 próximo passo, consiste na associação do paciente criado com o algum dos grupos de pesquisa nos quais o usuário pertence. Finalmente, o usuário seleciona que quer salvar o novo paciente e o mesmo é armazenado no sistema. A Figura 12 mostra o diagrama de caso de uso para criação de um novo paciente no sistema.

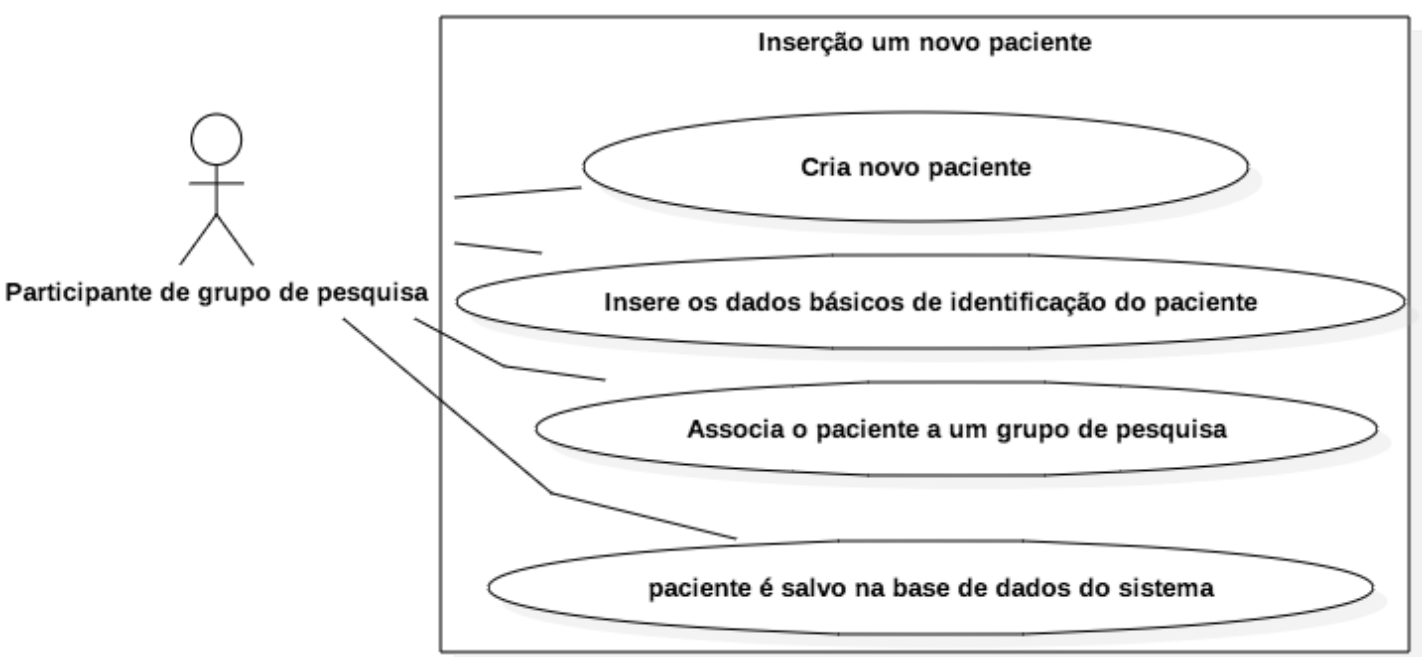

Figura 12 Diagrama de caso de uso para inserção de um novo paciente no sistema.

O próximo diagrama de caso de uso descreve o fluxo de ações que o usuário deve realizar para que ele consiga editar os dados de um determinado paciente. Primeiramente, na interface de listagem de pacientes, o usuário deve selecionar um paciente para edição. Em seguida, o usuário seleciona qual formulário de dados o paciente ele deseja editar. Após a seleção, o formulário com os campos editáveis será exibido para que o usuário faça as modificações que ele deseja, e após ter selecionado que deseja salvar as alterações, os novos dados são salvos no sistema. A Figura 13 demonstra o diagrama de caso de uso para alteração dos dados de um paciente. 


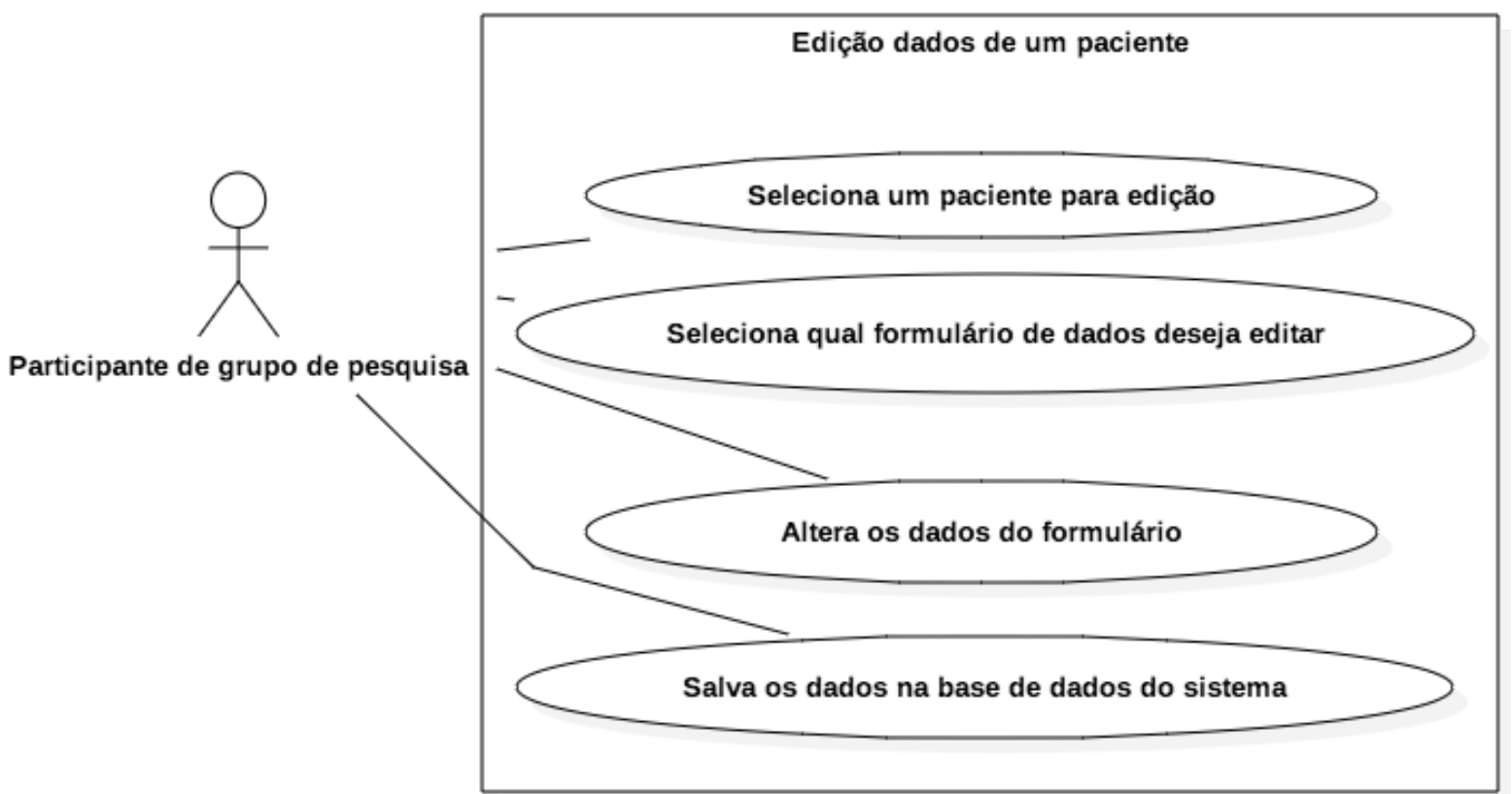

Figura 13 Diagrama de caso de uso para edição de dados de um paciente.

O próximo caso de uso ilustra as ações tomadas por um usuário para inserir um novo formulário de dados para um determinado paciente. Como no exemplo anterior, o usuário precisa selecionar o paciente no qual o novo formulário será inserido. A partir daí, o usuário poderá selecionar qual formulário ele deseja inserir e então a interface com os campos relativos ao tipo de formulário será exibida. Finalmente, o usuário precisará salvar as alterações para que os dados sejam armazenados no sistema. A Figura 14 a seguir mostra o diagrama de caso de uso para inserção de um novo formulário de dados para um paciente.

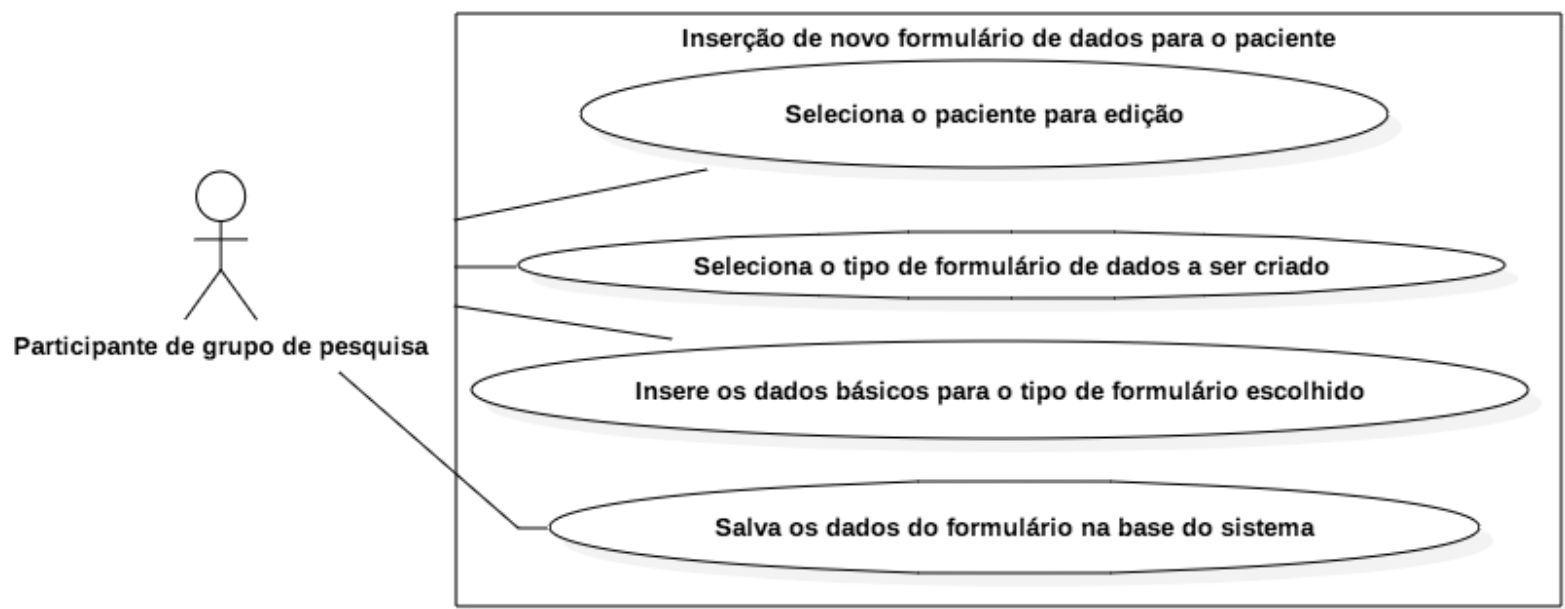

Figura 14 Diagrama de caso de uso para inserção de um novo formulário de dados para um paciente selecionado pelo usuário. 
O próximo caso de uso se refere à ação de inserir dados de um novo biomaterial no BioBank Warden. Na primeira etapa, o usuário acessa a guia biomateriais presente na interface do sistema e adiciona as informações do biomaterial como tipo de amostra, processamento, quantidade ou volume do biomaterial. Em seguida, o usuário deve associar o biomaterial a um paciente cadastrado no sistema, o significando que o biomaterial foi colhido deste paciente. Também é necessário que o usuário informe a localização física do biomaterial por meio da identificação do centro, freezer, prateleira, caixa e posição na caixa que o biomaterial está. Finalmente os dados poderão ser salvos no sistema caso o usuário deseje. A seguir está a Figura 15 ilustrando o diagrama de caso de uso para inserção de um novo biomaterial no sistema.

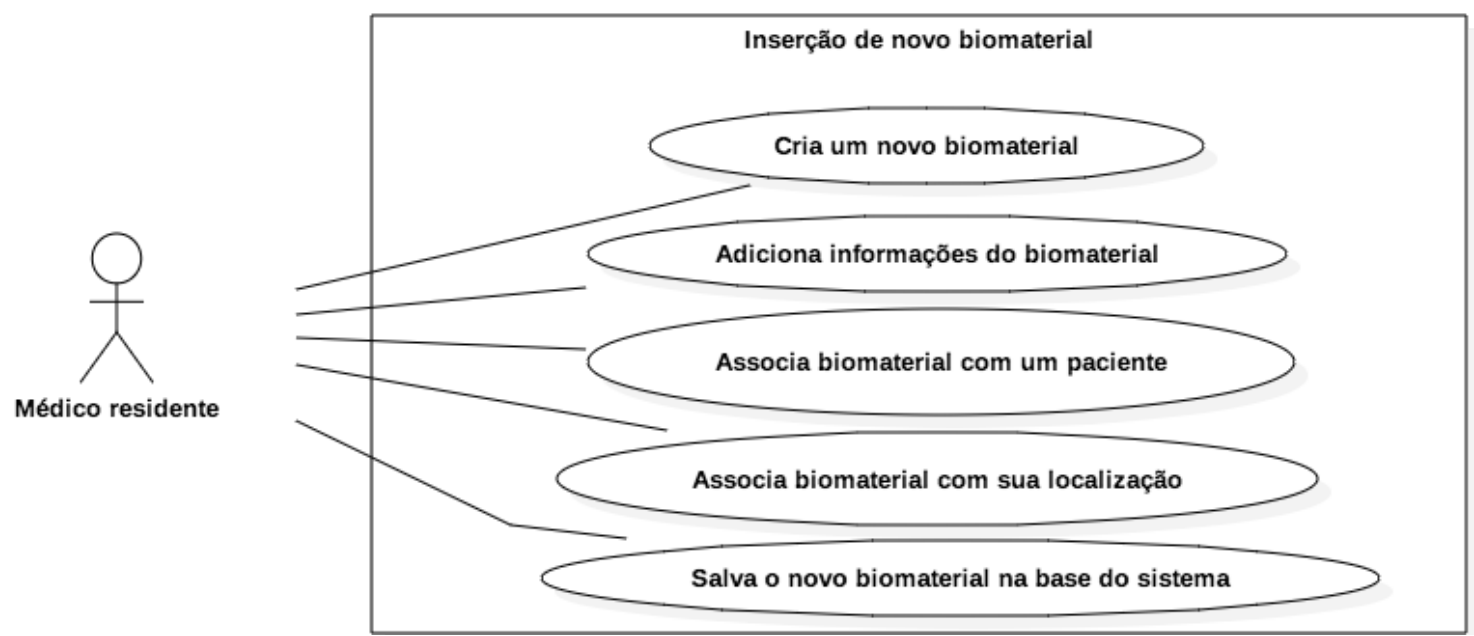

Figura 15 Diagrama de caso de uso para inserção de um novo biomaterial.

O último diagrama de caso de uso representa os passos necessários para que o usuário faça uma requisição para um determinado volume de um biomaterial de sua escolha. Primeiramente o usuário deve acessar a lista de biomateriais, selecionar o biomaterial de interesse e selecionar a opção de requisitar uma quantia do mesmo. Em seguida, será exibida interface na qual o usuário determina a quantia pretendida para a requisição do biomaterial, e onde opcionalmente, ele pode inserir detalhes e observações com a finalidade de uso do biomaterial. Após inseridos os dados ele pode confirmar a requisição e após confirmada ele deve aguardar pela resposta de um dos responsáveis pela liberação da amostra que pode responder positiva ou negativamente. Caso a requisição seja disponibilizada o usuário será notificado para retirar a amostra em um 
local indicado. A seguir está a Figura 16 ilustrando o diagrama de caso de uso para requisição de um biomaterial.

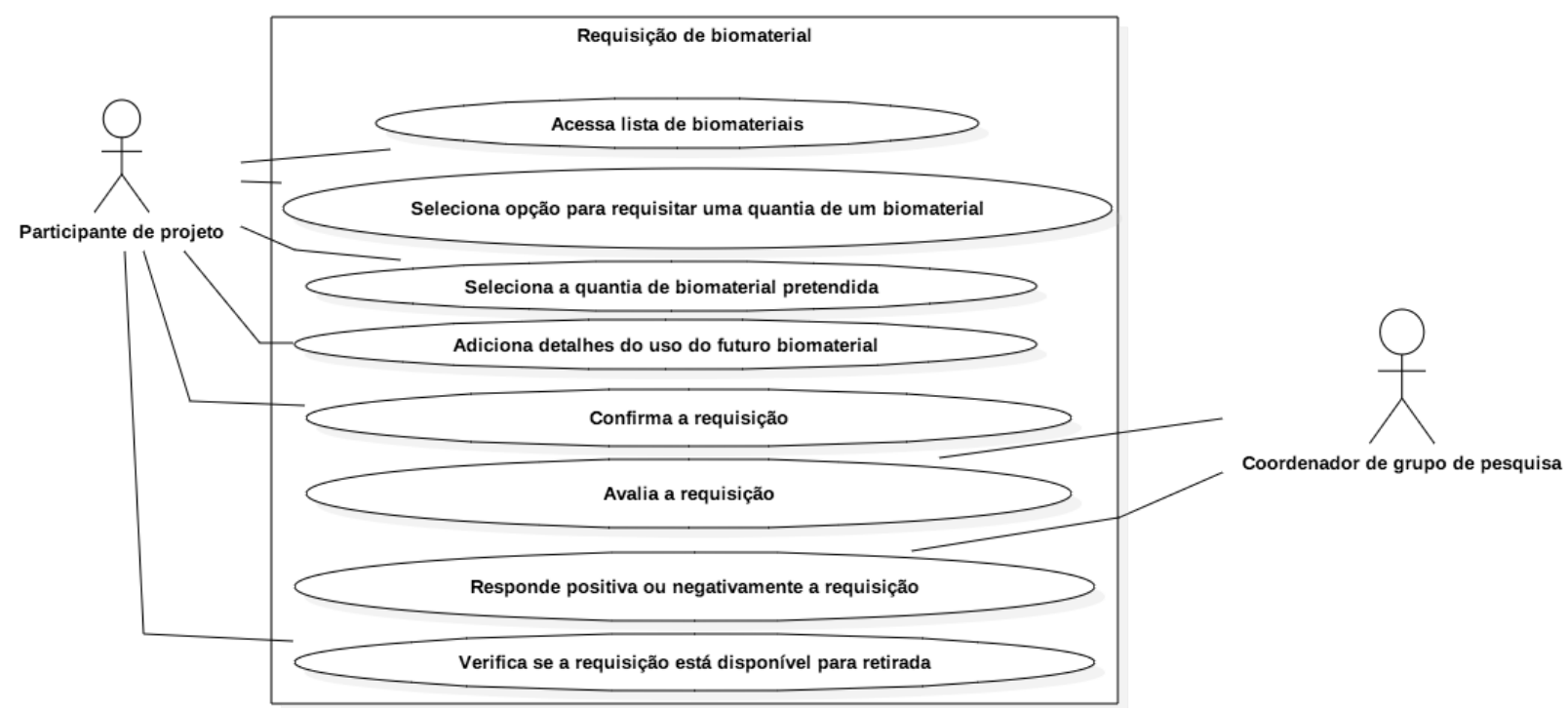

Figura 16 Diagrama de caso de uso para requisição de biomaterial. 


\subsubsection{Diagrama Entidade Relacionamento BioBank Warden}

Nesta seção será descrito o diagrama entidade relacionamento (DER) do BioBank Warden. Este diagrama apresenta as tabelas contidas no sistema gerenciador de bancos de dados utilizados pelo sistema e cada tabela terá sua função apresentada. A Figura 17 mostra o DER do BioBank Warden.

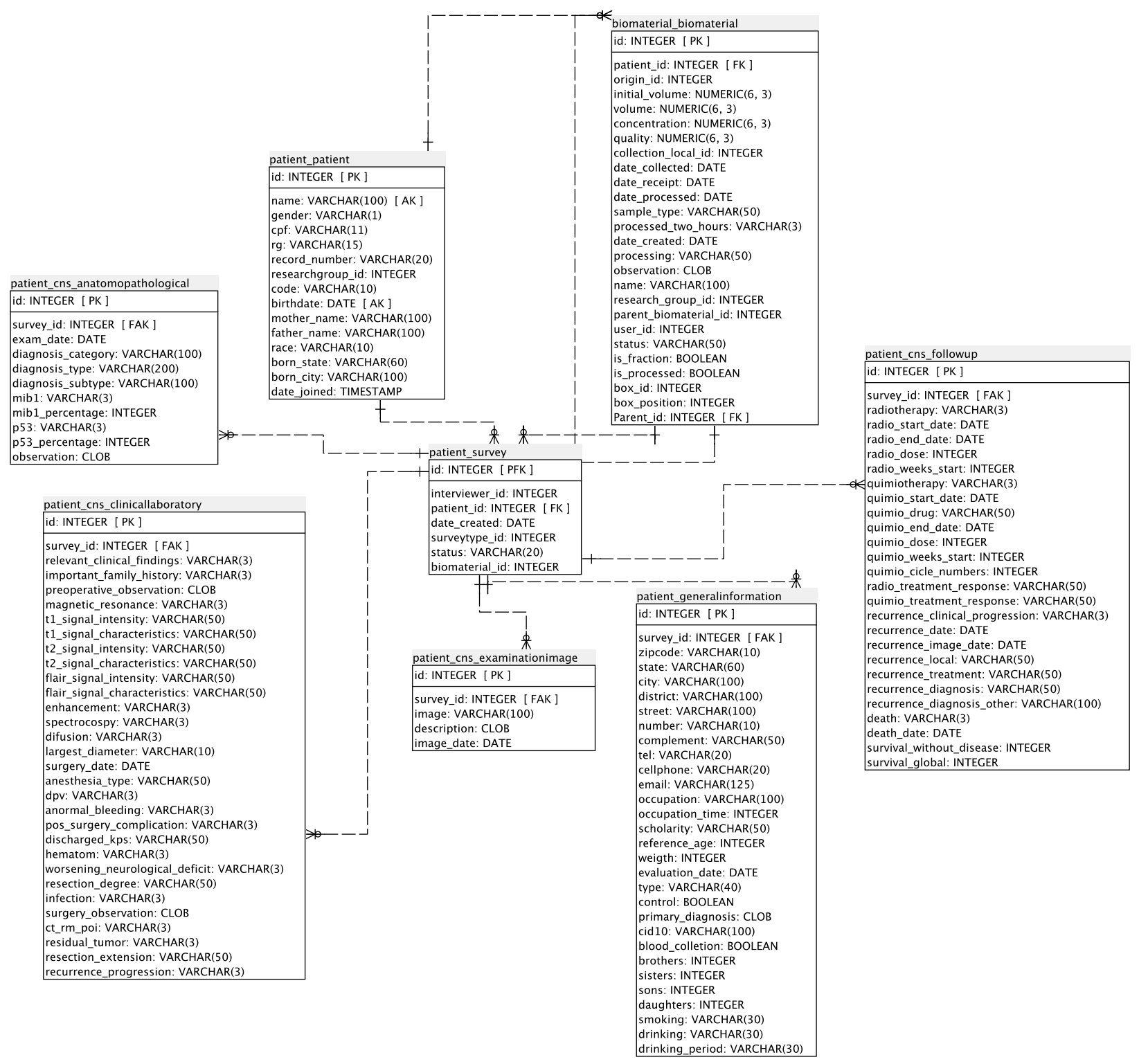

Figura 17 Diagrama entidade relacionamento das principais tabelas do sistema BioBank Warden. 


\section{Tabela patient}

A tabela patient armazena dados referentes as informações básicas de identificação de um determinado paciente como: RG, CPF, idade, sexo, data de nascimento, grupo de pesquisa de doença associado e etc. Todo paciente armazenado no sistema possui uma entrada nesta tabela.

\section{Tabela biomaterial}

É a tabela responsável por armazenar informações relacionadas a um determinado biomaterial como: paciente do qual foi colhido, origem, localização, quantidade, processamento, volume disponível, tipo de amostra e etc.

\section{Tabela survey}

Todos os formulários de dados clínicos criados no sistema precisam referenciar esta tabela. Seu papel é armazenar informações sobre o formulário como: usuário que realizou a inserção dos dados, data da inserção, paciente a quem os dados se referem, tipo do formulário e status de preenchimento do formulário (completo, ou incompleto).

\section{Tabela cns_anatomopathological}

Tabela que contém dados clínicos anatomopatológicos de sistema nervoso central. Referencia a tabela survey e também possui informações como: tipo, categoria e subtipo do diagnóstico, data do exame, porcentagem de proteínas e observações.

\section{Tabela cns_examinationimage}

Armazena informações sobre um exame com imagens para a especialidade de sistema nervoso central. Seus atributos são: caminho para imagem no sistema de arquivos, descrição e data de aquisição.

\section{Tabela cns_clinicallaboratory}

É a tabela responsável por armazenar informações sobre o formulário de dados clínicos laboratoriais para pesquisas na área de cabeça e pescoço. Pode ter seus dados subdivididos em três tipos: pré-operatório, cirurgia e pós-operatório. 


\section{Tabela cns_followup}

Representa os dados presentes nos formulários de acompanhamento do paciente para a especialidade de sistema nervoso central. Entre seus atributos pode-se listar: data de início de quimioterapia ou radioterapia, data de óbito, recorrência do tumor, dias de tratamento até a morte e etc.

\section{Tabela generalinformation}

Esta tabela contém dados relativos as informações gerais do paciente e pode ser reutilizada por inúmeras especialidades cadastradas no sistema. Seus atributos compreendem: dados demográficos como endereço, estado, bairro e cep; dados socioeconômicos como ocupação e nível de escolaridade; informações pessoais como idade, peso, diagnóstico primário, se o paciente é caso ou controle; informações familiares como número de irmãos, filhos e histórico de doenças familiares; histórico pessoal relevante como uso de tabaco e álcool.

\subsection{Integração do framework IPTrans A2Tool e BioBank Warden}

O IPTrans consiste em uma plataforma integrativa flexível que permite que dados de diferentes fontes sejam integrados e pesquisados de forma eficiente. Porém, o seu projeto inicial não teve como objetivo oferecer funcionalidades que permitissem aos usuários realizar análises sobre os dados armazenados em suas bases. 0 papel fundamental da ferramenta IPTrans A2Tool é prover um meio simples, porém robusto, de acesso e análise dos dados clínicos e biomoleculares agregados por meio do uso do framework IPTrans. Estes dados, como explicado anteriormente, são provenientes de quaisquer base de dados que sejam disponibilizadas nos formatos de importação aceitos pelo IPTrans.

Pensando em utilizar um exemplo de mundo real para testar o IPTrans A2Tool, foi desenvolvido o BioBank Warden, um sistema robusto e flexível de armazenamento de dados clínicos e amostras. No contexto do IPTrans, o BioBank Warden pode ser tido como uma dentre as bases legadas que têm seu conteúdo integrado pela plataforma. Por isso os dados clínicos e biomoleculares dos pacientes de sistema nervoso central presentes no BioBank Warden foram inseridos na base de dados do framework IPTrans 
para serem utilizados como teste da capacidade de análise da ferramenta IPTrans A2Tool. 


\section{Capítulo 5 Materiais e Métodos}

Neste capítulo serão apresentadas as fontes de dados que foram utilizadas para validação do IPTrans A2Tool e do BioBank Warden, bem como suas respectivas metodologias de desenvolvimento. Além disso serão descritas as plataformas e ferramentas de desenvolvimento utilizadas na construção de cada um dos sistemas.

\subsection{Fontes de dados IPTrans A2Tool}

O IPTrans A2Tool, devido ao fato de ter sua estruturação baseada no framework IPTrans, suporta variados tipos de entrada de dados. Para validarmos a capacidade da ferramenta em integrar e analisar dados oriundos de diversas fontes, foram escolhidas duas fontes de dados principais.

A primeira fonte de dados é o Banco de Tumores do Sistema Nervoso, um subprojeto do projeto Genoma Clínico (2011) que partiu de uma inciativa da Divisão de Neurocirurgia da Faculdade de Medicina de Ribeirão Preto da Universidade de São Paulo (FMRP-USP). Os dados contém números de expressão gênica de microarray e os dados clínicos dos pacientes dos quais foram extraídas as amostras, todos relacionados a cânceres do sistema nervoso central . Os dados clínicos foram armazenados pelo sistema BioBank Warden, desenvolvido em paralelo ao framework IPTrans A2Tool.

A outra fonte de dados é o The Cancer Genome Atlas (TCGA), um projeto supervisionado pelo National Cancer Institute (NCI) e pelo National Human Genome Research Institute fundados pelo governo norte-americano. Essa iniciativa tem o intuito de catalogar mutações genéticas responsáveis pelo câncer utilizando sequenciamento genômico e bioinformática . Os dados compreendem dados clínicos e biomoleculares, já normalizados, de pacientes com câncer de mama e colo-retal.

É importante ressaltar que ambas as fontes de dados já estão com seus dados normalizados, de forma que nenhuma normalização é realizada pelo IPTrans A2Tool.

Desta forma, o sistema pode ser testado utilizando base de dados públicas e com variações significativas entre seus dados. 


\subsection{Fontes de dados Biobank Warden}

O BiobankWarden, por ser um projeto abrangente e que visa o gerenciamento dos dados de diversos projetos pertencentes ao NAPs Biobanco e CISBi, conta com variadas fontes de dados. No entanto, para a fase de testes do sistema, os dados utilizados foram coletados de pacientes de oncologia do sistema nervoso central que realizaram suas consultas no Hospital das Clínicas da Faculdade de Medicina de Ribeirão Preto da Universidade de São Paulo (HCTFMRP USP). Estes dados são compostos por questionários contendo informações do paciente tais como, identificação, dados gerais (local onde reside, diagnóstico primário e histórico familiar), dados clinico-laboratoriais, anatomopatológicos, acompanhamento do paciente e exames com imagens. Além disso são armazenadas informações de estocagem de amostras biológicas extraídas dos mesmos pacientes, tais como volume, tipo de tecido e tipo de processamento.

\subsection{Metodologia de desenvolvimento dos sistemas}

Ambos os sistemas foram desenvolvido usando a metodologia de desenvolvimento iterativa incremental, na qual, inicialmente, é estabelecida uma pequena lista de requisitos básicos do sistema que são desenvolvidos de forma iterativa com o intuito de criar novas versões do sistema a partir do retorno dos usuários, com mais funcionalidades que a anterior, até se alcançar a implementação completa do sistema. 0 sistema iterativo incremental pode ser subdividido em três etapas:

1. Inicialização: nesta etapa é desenvolvida uma versão base do sistema que o usuário possa avaliar. Esta versão base deve apresentar os aspectos mais importantes do software e prover soluções simples de serem desenvolvidas e compreendidas.

2. Criação de lista de controle: esta lista contém todas as tarefas que necessitam ser realizadas no projeto, tais como, novas características, melhorias. Esta lista deve ser continuamente revisada.

3. Etapa iterativa: envolve redefinições do projeto, execução das tarefas na lista de controle e a análise da versão atual do sistema. Cada iteração deve ser modular, simples, direta e suportar inserções de novas tarefas por meio da modificação da lista de controle do projeto. A versão do sistema é avaliada por meio da interação com os usuários do sistema. 


\subsection{Plataformas e ferramentas de desenvolvimento}

Para a implementação de ambos sistemas foi utilizado o framework da linguagem de programação Python (VAN ROSSUM, 2011) para desenvolvimento web denominado Django (HOLOVATY, 2009). Esse framework utiliza o paradigma de design de software conhecido por Model View Controller (MVC) (KRASNER 1988), muito utilizado para desenvolvimento de aplicações web, além de possuir facilidades para criação e manipulação de bancos de dados.

Como ambiente de desenvolvimento de software foi utilizado o Sublime Text 2, que é bastante leve, versátil e conta com funcionalidades que permitem um rápido desenvolvimento.

Finalmente, como sistema gerenciador de bancos de dados utilizamos o PostgreSQL (versão 9.0), por ser um SGBD confiável, robusto e gratuito. 


\section{Capítulo 6 - Resultados}

Neste capítulo serão apresentados os resultados obtidos com a implementação do framework de análise de dados clínicos e biomoleculares IPTrans A2Tool e também para o sistema de gerenciamento de dados clínicos e amostras biomoleculares o BioBank Warden.

\subsection{Resultados IPTrans A2Tool}

Considerando a proposta inicial de modelagem e implementação do conjunto de funcionalidades descritas no Capítulo 4, como resultado final, foi construído um sistema de análise de dados clínicos e biomoleculares baseado no framework de integração de dados IPTrans. O sistema IPTrans A2Tool permite que usuários sem conhecimento avançado em ferramentas de bioinformática possam realizar análises sobre dados clínicos e biomoleculares que estejam presentes na base de dados do IPTrans. Desta forma, o IPTrans A2Tool permite:

- Realização de experimentos de análise diferencial de expressão gênica entre grupos de pacientes selecionados;

- Visualização dos dados provenientes das análises;

- Inferência de regras de associação baseada em critérios definidos pelo usuário.

\section{Interfaces do usuário}

A seguir serão apresentadas as interfaces de usuário mais importantes presentes no sistema IPTrans A2Tool.

Primeiramente, é apresentada ao usuário uma interface na qual ele pode selecionar se pretende realizar análises de expressão diferencial, ou mineração de dados (extração de regras de associação). Ao selecionar análises de expressão diferencial, é exibida uma tela que contém no seu topo os campos para seleção de plataforma de microarray (Affymetrix, ou Agilent).A partir daí é exibida para o usuário uma lista de múltipla escolha na qual ele pode selecionar quais bases de dados ele deseja analisar. Após selecionar as bases, de forma automática, são exibidos os campos de dados clínicos 
que podem ser usados como filtros para a seleção dos dois grupos confrontados na análise. Os campos mostrados são os que possuem correspondentes entre as bases de dados associadas pelo IPTrans e, por isso, podem ter seus dados comparados na análise. Em seguida, o usuário pode selecionar quais análises ele deseja realizar, dentre as seguintes: heatmap de expressão diferencial, volcano plot, matriz de consenso de agrupamentos e box plot. Cada análise permite ao usuário selecionar alguns parâmetros. No heatmap de expressão diferencial, o usuário pode selecionar a quantidade de genes que devem ser exibidos. Já no volcano plot, o usuário pode escolher o p-valor e o foldchange usados como pontos de corte na análise. Para matriz de consenso de agrupamentos o usuário pode escolher a quantidade máxima de grupos que deve ser testada. E, finalmente para o box plot, o usuário pode selecionar os genes para os quais ele deseja ver o box plot. A figura 18 mostra esta interface.

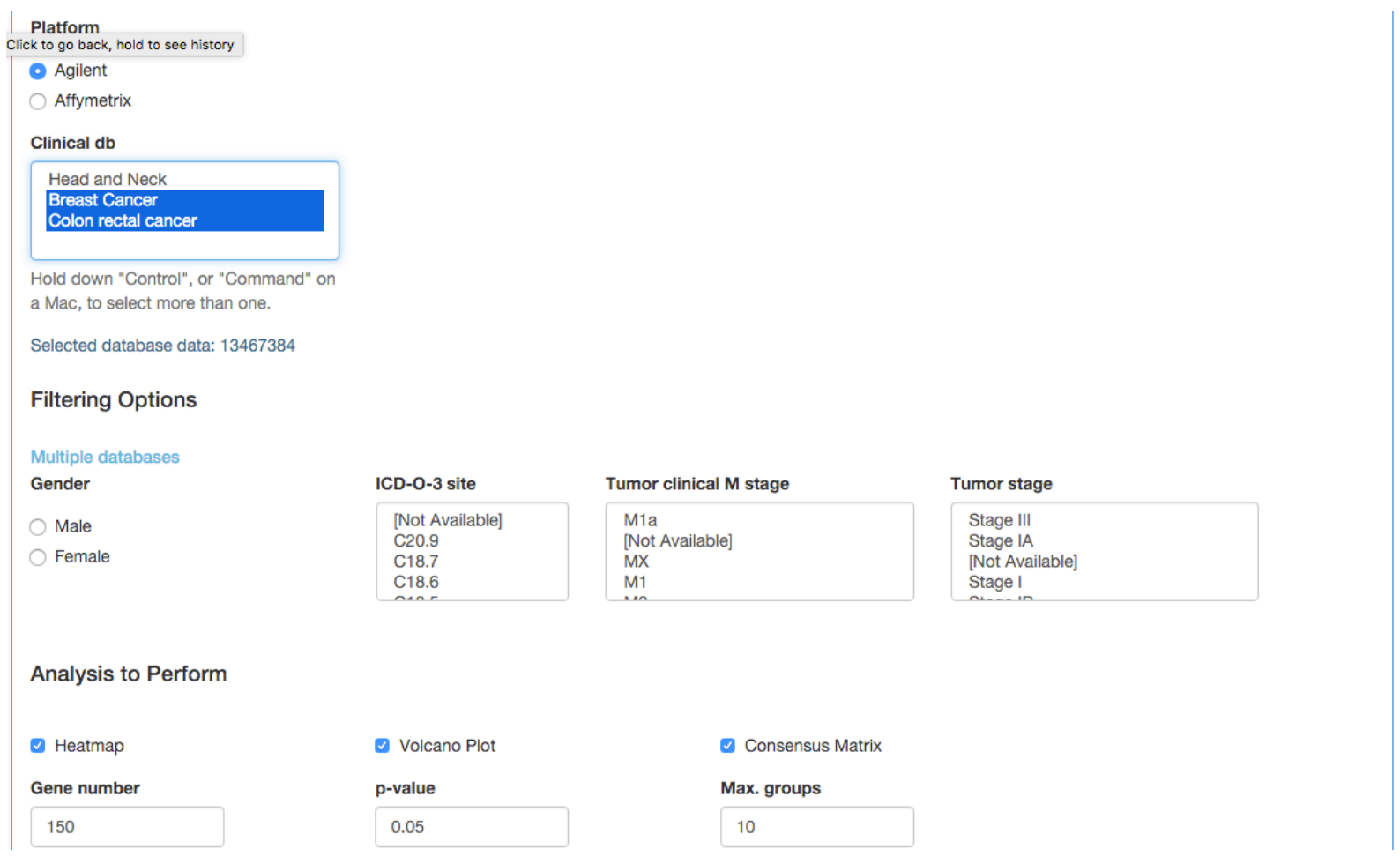

Figura 18 - Interface de seleção de base de dados e análises.

Após decidir realizar as análises, o usuário é levado para uma tela que exibe os resultados das análises. É importante ressaltar que elas podem ser realizadas de forma simultânea e o usuário pode visualizar o resultado de todas em apenas uma tela para facilitar a complementaridade dos experimentos. Independentemente das análises selecionadas, é exibida no topo da tela de resultados uma tabela expansível contendo dados de expressão gênica para os genes utilizados na análise como: valor médio de 
expressão, p-valor, p-valor ajustado, entre outros. Além disso são exibidos as imagens contendo os gráficos correspondentes as análises selecionadas pelo usuário. Todas as imagens podem ser baixadas para que o usuário as use da forma que for melhor para ele. A figura 19 mostra a interface de resultados de análise e a tabela com os dados para os genes.

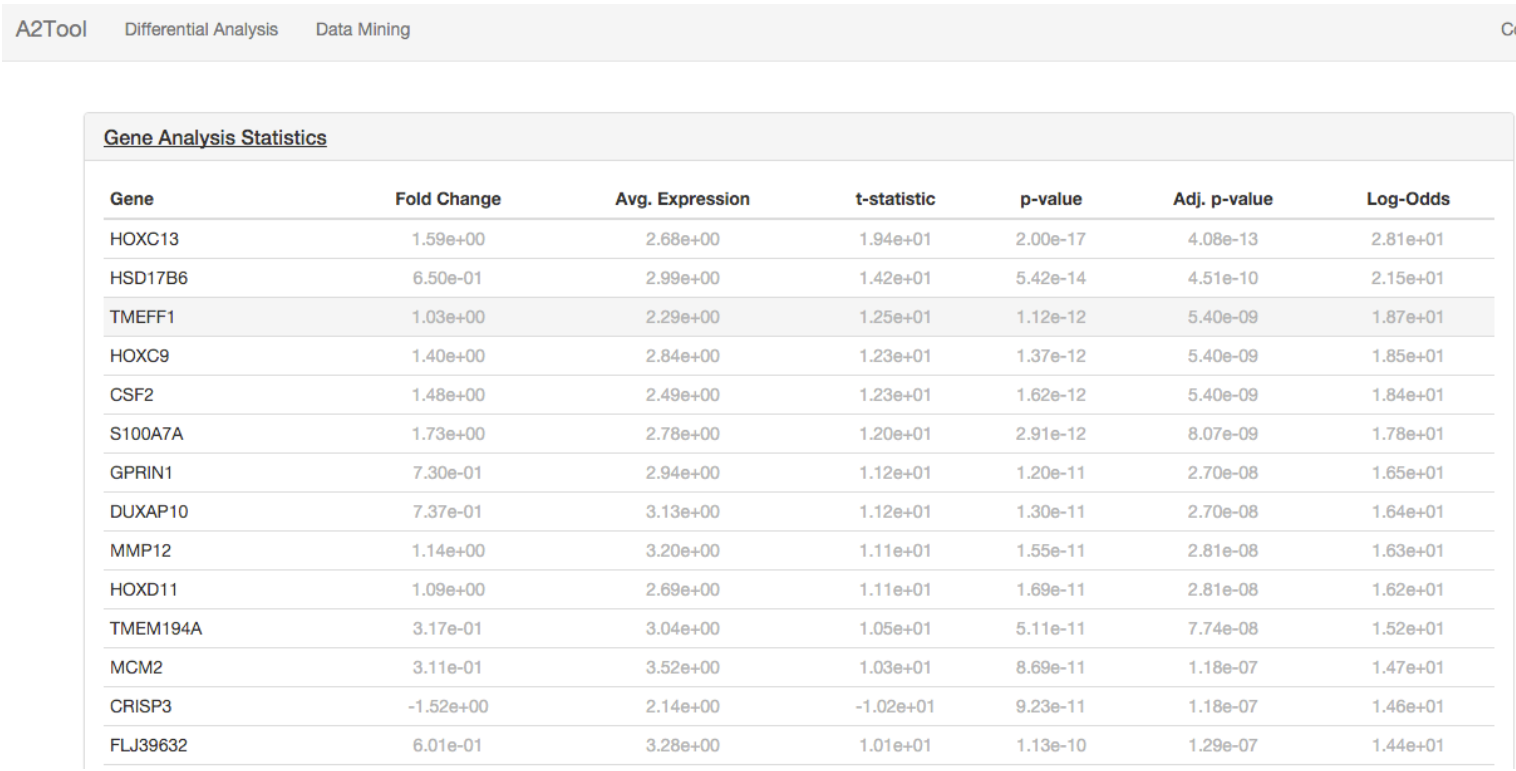

Figura 19 Tabela com dados para cada gene utilizado na análise

A seguir, a figura 20 exibe a interface com gráficos para heatmap expressão diferencial e volcano plots.

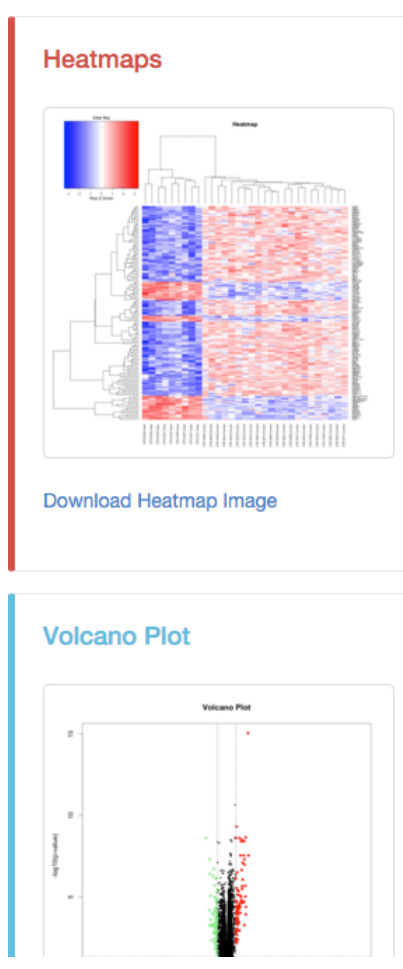

Figura 20 Interface com os gráficos para heatmap e volcano plot. 
A outra opção que o usuário pode escolher na tela inicial é a de mineração de dados. Esta interface permite ao usuário escolher e filtrar os dados da mesma forma que na interface para análises diferenciais. No entanto, os dados selecionados serão utilizados para a extração de regras de decisão do conjunto de dados. Como parâmetros de entrada para o algoritmo a priori o usuário pode definir a confiança, o suporte e o número de itens mínimos necessários para que uma regra seja válida, como explicado na seção 2.2 do capítulo 2 deste trabalho. A figura 21 ilustra a interface de seleção e configuração para extração de regras de associação.

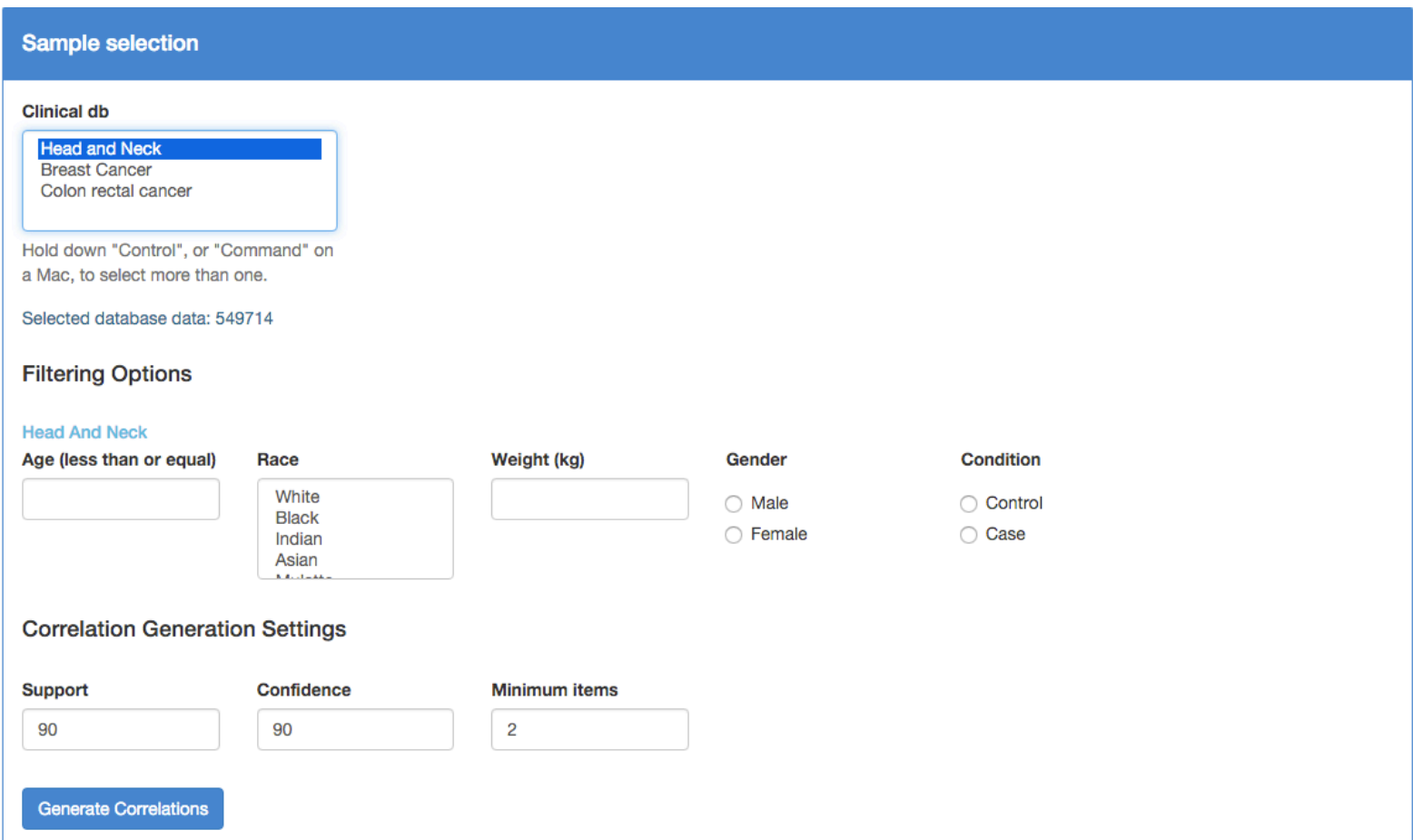

Figura 21 - Interface de configuração do algoritmo de extração de regras de decisão.

Após selecionar que deseja gerar as regras de decisão o algoritmo iniciará a mineração dos dados e ao final de sua rotina será exibida ao usuário uma interface contendo uma tabela com as possíveis regras encontradas e seu suporte. A figura 22 mostra a interface com as regras de associação extraídas para os pacientes com câncer de mama. 


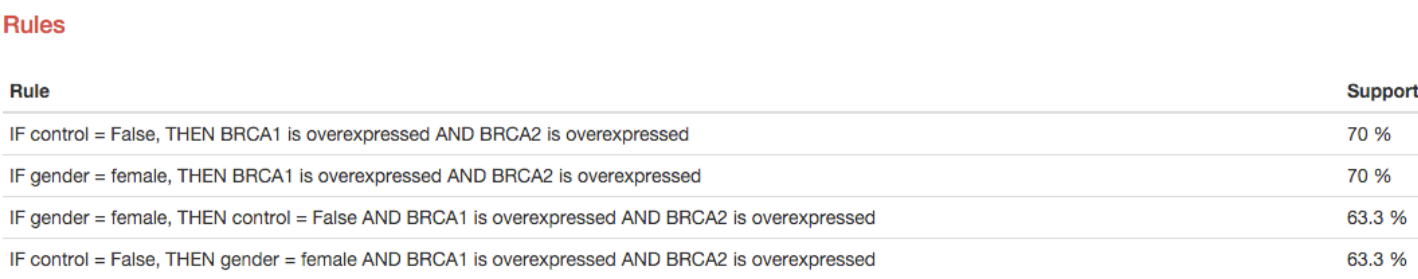

Figura 22 - Regras obtidas para todos os dados cujos pacientes eram portadores de câncer de mama.

\section{Avaliação de usabilidade dos usuários}

Para avaliar a usabilidade do framework IPTrans A2Tool, foi aplicado um questionário contendo perguntas sobre a usabilidade geral do sistema. As perguntas têm o intuito de averiguar se o sistema é amigável e se atende às necessidades de seus possíveis usuários da área biomédica. Para tanto, foram convidados três usuários do sistema e foi aplicado um questionário composto pelos seguintes itens:

1. Foi simples utilizar este sistema;

2. Sou capaz de realizar o meu trabalho de forma eficaz usando este sistema;

3. Me senti confortável usando este sistema;

4. Foi fácil aprender a usar este sistema;

5. Acredito que meu trabalho será mais produtivo com o uso deste sistema;

6. Quando cometi algum erro no sistema consegui resolver rápida e facilmente;

7. É fácil encontrar as informações que eu preciso;

8. As informações visuais que o sistema oferece são fáceis de entender;

9. As informações que o sistema oferece são eficazes em me ajudar a completar as tarefas;

10. A organização de interface do sistema é clara;

11. A interface do sistema é agradável;

12. No geral, eu estou satisfeito com o sistema;

Estas questões podem ser respondidas com valores que variam de 1 até 7 , sendo que o número 1 significa que o usuário discorda fortemente enquanto 7 significa que o usuário concorda fortemente. Além dos valores também está disponível a opção "não se aplica", usada quando o usuário não sabe opinar a respeito da pergunta. 
O grupo de usuários que recebeu os testes é composto por parte dos médicos, pesquisadores e pós graduandos que ajudaram a definir os requisitos de ambos os sistemas. A seguir é exibida uma tabela com o resultado das questões para cada usuário.

Tabela 5 - Tabela com as respostas de cada usuário para o questionário de usabilidade

\begin{tabular}{|l|c|c|c|}
\hline Perguntas & Usuário & Usuário 2 & Usuário 3 \\
\hline $\mathbf{1}$ & 7 & 6 & 6 \\
\hline $\mathbf{2}$ & 7 & 4 & 5 \\
\hline $\mathbf{3}$ & 5 & 7 & 6 \\
\hline $\mathbf{4}$ & 5 & 7 & 7 \\
\hline $\mathbf{5}$ & 7 & 6 & 6 \\
\hline $\mathbf{6}$ & NA & NA & NA \\
\hline $\mathbf{7}$ & 4 & 7 & 5 \\
\hline $\mathbf{8}$ & 7 & 6 & NA \\
\hline $\mathbf{9}$ & 6 & 5 & 7 \\
\hline $\mathbf{1 0}$ & 7 & 6 & 7 \\
\hline $\mathbf{1 1}$ & 7 & 5 & 6 \\
\hline $\mathbf{1 2}$ & 5 & 6 & 6 \\
\hline
\end{tabular}

Dadas as resposta obtidas pela aplicação do questionário, podemos constatar que o sistema apresenta uma usabilidade satisfatória para a realização de suas tarefas.

\subsection{Resultados BioBank Warden}

O presente trabalho conseguiu implementar as funcionalidades propostas para o sistema de gerenciamento de dados clínicos e amostras biomoleculares BioBank Warden. 0 resultado desta implementação consiste em um sistema web que permite:

- armazenar dados clínicos de pacientes em diversos tipos de questionário;

- controlar e gerenciar o acesso dos dados de pacientes por meio da criação de grupos de pesquisa de doenças com os quais os pacientes estão associados, e de um conjunto de permissões de acesso para os usuários;

- gerenciar amostras biológicas colhidas dos pacientes, permitindo que os usuários façam requisições dessas amostras aos seus grupos responsáveis. 
Em decorrência do trabalho com o BioBank Warden, foi publicado um artigo científico na revista internacional Computers in Biology and Medicine cujo título "BioBankWarden: A web-based system to support translational cancer research by managing clinical and biomaterial data", e DOI http://dx.doi.org/10.1016/j.compbiomed.2015.04.008.

\section{Interfaces de usuário}

Nesta seção serão descritas as principais interfaces de usuário presentes no sistema BioBank Warden.

A interface de listagem dos pacientes conta com informações básicas de cada paciente, tais como nome, código no sistema, data de aniversário, centro no qual o paciente pertence, e grupo de coleta de biomaterial associado. Os pacientes exibidos nesta interface são agrupados pelos grupos de coleta de biomaterial nos quais o usuário pertence, visando facilitar a pesquisa por determinados pacientes. Também pode-se perceber a presença de elipses coloridas que indicam quais questionários o paciente já possui preenchidos completamente (cor verde), quais estão preenchidos de forma incompleta (cor amarelo) e quais o paciente ainda não tem informações (cor cinza). Para a inserção de um novo questionário para o paciente, o usuário pode clicar no símbolo contendo um sinal de adição, a partir daí será solicitado ao usuário qual questionário ele deseja inserir, e finalmente o usuário será direcionado a interface de inserção do questionário escolhido. Outra possibilidade é que novos pacientes sejam adicionados por meio desta interface além dos pacientes listados poderem ser filtrados pelos respectivos nomes e grupo de coleta de biomateriais. Finalmente, se for necessária a impressão de algum dos questionários para preenchimento, o usuário pode clicar no ícone da impressora e a partir daí selecionar qual questionário ele deseja imprimir.

A figura 23 mostra a interface de listagem de paciente contendo as características acima citadas. 


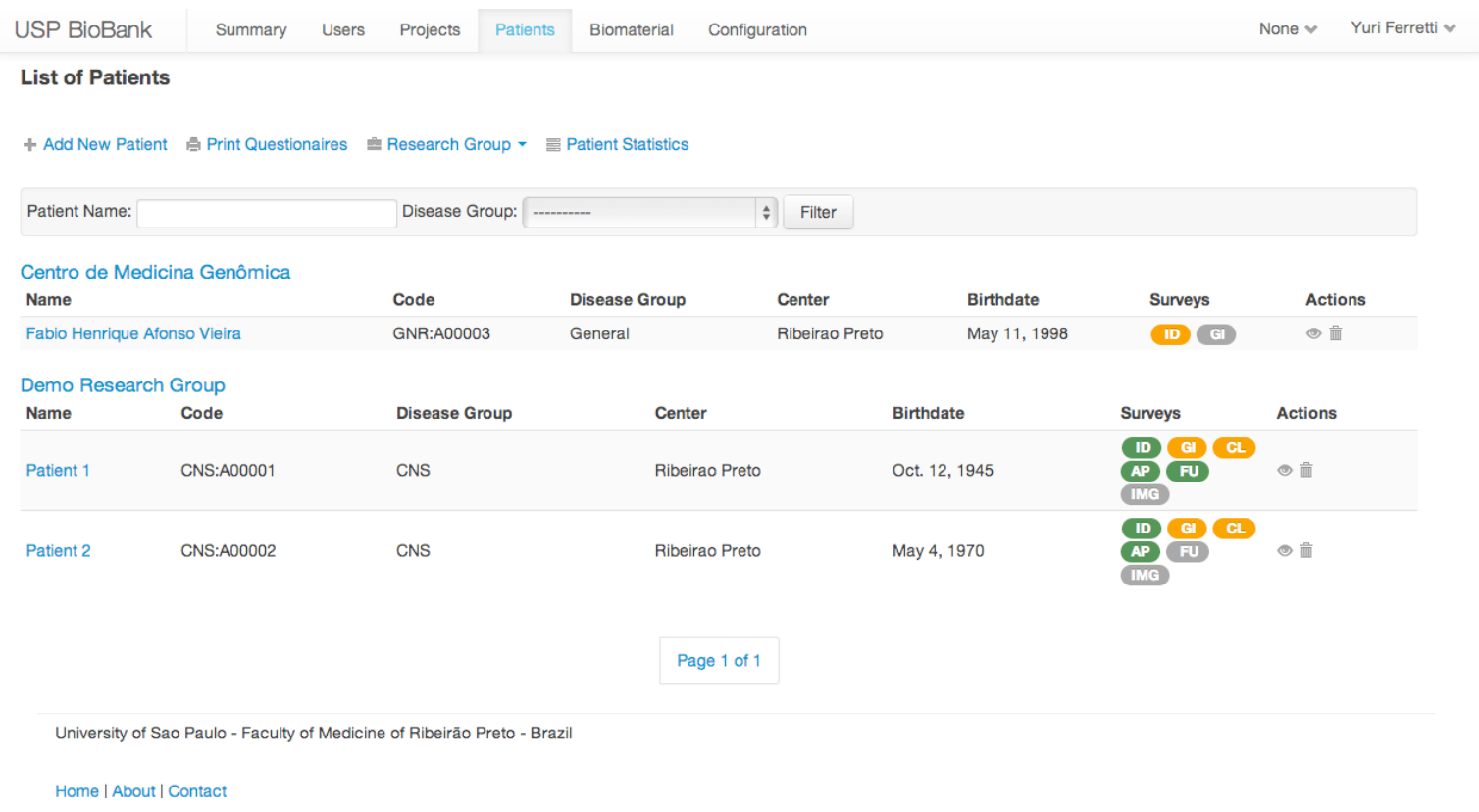

Figura 23 - Interface de listagem de pacientes

Como decorrência da seleção de qual questionário de dados clínicos o usuário deseja inserir, é exibida uma interface contendo o formulário para preenchimento dos dados. A figura 24 mostra a interface de inserção de dados clinico-laboratoriais.

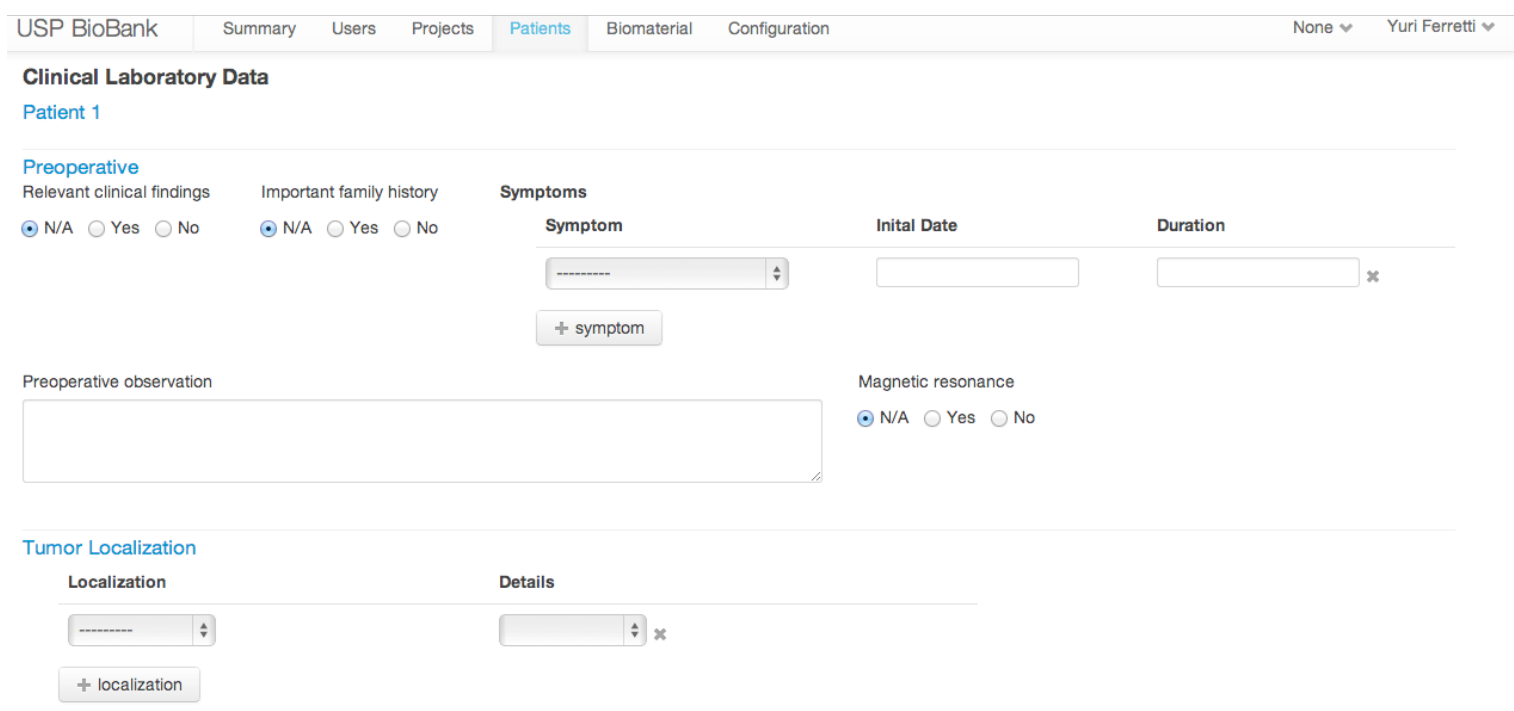

Figura 24 Interface de inserção de dados clinico-laboratoriais.

Como proposto, foi implementada uma interface de gerenciamento de biomateriais, tornando possível aos usuários do BioBank Warden requisitar, inserir e visualizar dados sobre biomateriais. 
Esta interface oferece ao usuário uma listagem de biomateriais na qual estão presentes algumas informações a respeito de cada biomaterial listado, tais como volume disponível, tipo de tecido da amostra (sangue, soro, tumor, etc), processamento do biomaterial, e finalmente se o biomaterial possui sub-alíquotas denotadas por elipses cinzas contendo o tipo de processamento das mesmas. Além disso, a interface oferece no lado esquerdo, uma lista contendo filtros que permitem ao usuário filtrar os biomateriais exibidos a partir de determinadas características clínicas presentes nos pacientes dos quais os biomateriais foram coletados. No lado direito da interface podemos ver um grupo de ícones exibidos para cada biomaterial, que representam ações que podem ser tomadas pelo usuário, tais como edição, visualização, deleção, requisição de um volume do biomaterial e marcação do biomaterial como "sem volume disponível". A figura 25 ilustra a interface de listagem de biomateriais.

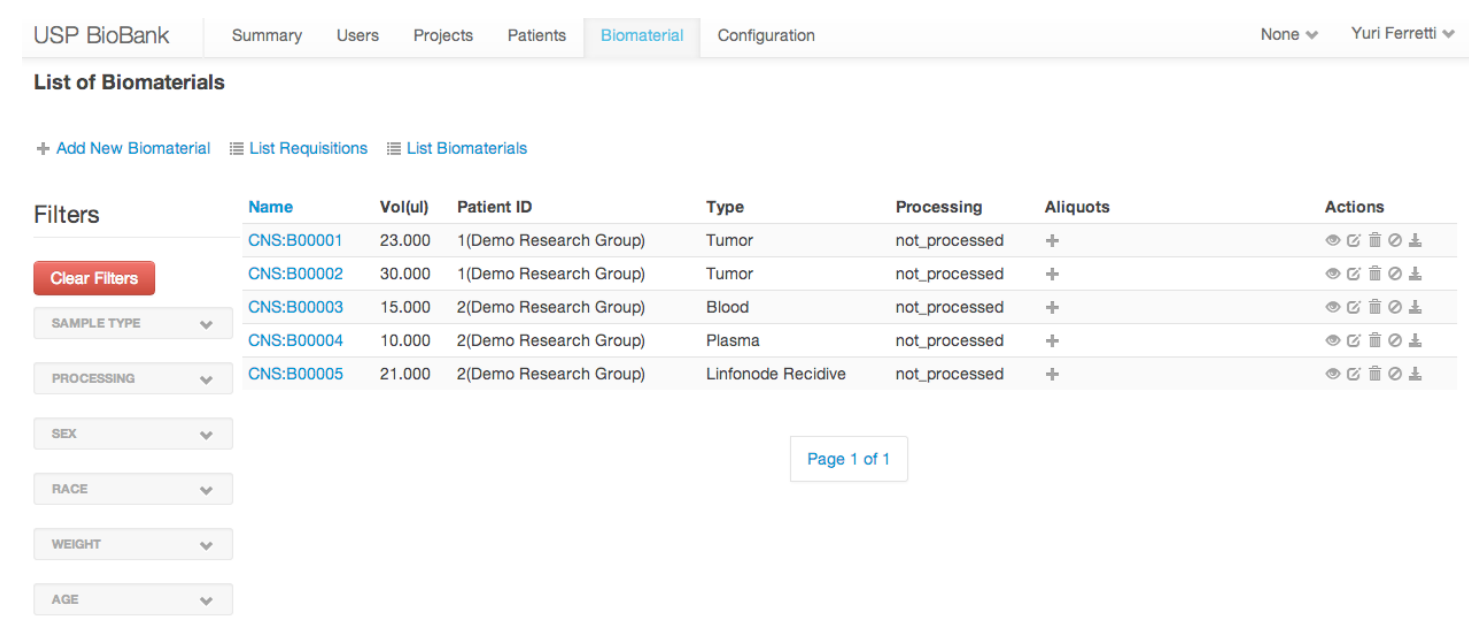

Figura 25 - Interface mostrando a listagem de biomateriais

O BioBankWarden conta com uma interface própria para requisição de alíquotas de biomateriais. Nesta interface o usuário pode especificar o volume requisitado, qual projeto será beneficiado com a alíquota e outras observações que ele julgue importante para a aprovação da requisição. Após a requisição ser efetuada, o coordenador do grupo de coleta de biomaterial responsável pelo biomaterial será notificado quanto ao deferimento ou não da requisição, sendo possível para o coordenador especificar qual volume será liberado e outras observações a respeito da resposta para a requisição. Automaticamente o sistema cancela requisições que não forem retiradas dentro de um 
prazo de trinta dias a partir do deferimento do pedido, tornando possível que outros usuários façam a requisição da amostra. A figura 26 mostra a interface de requisição de alíquota.

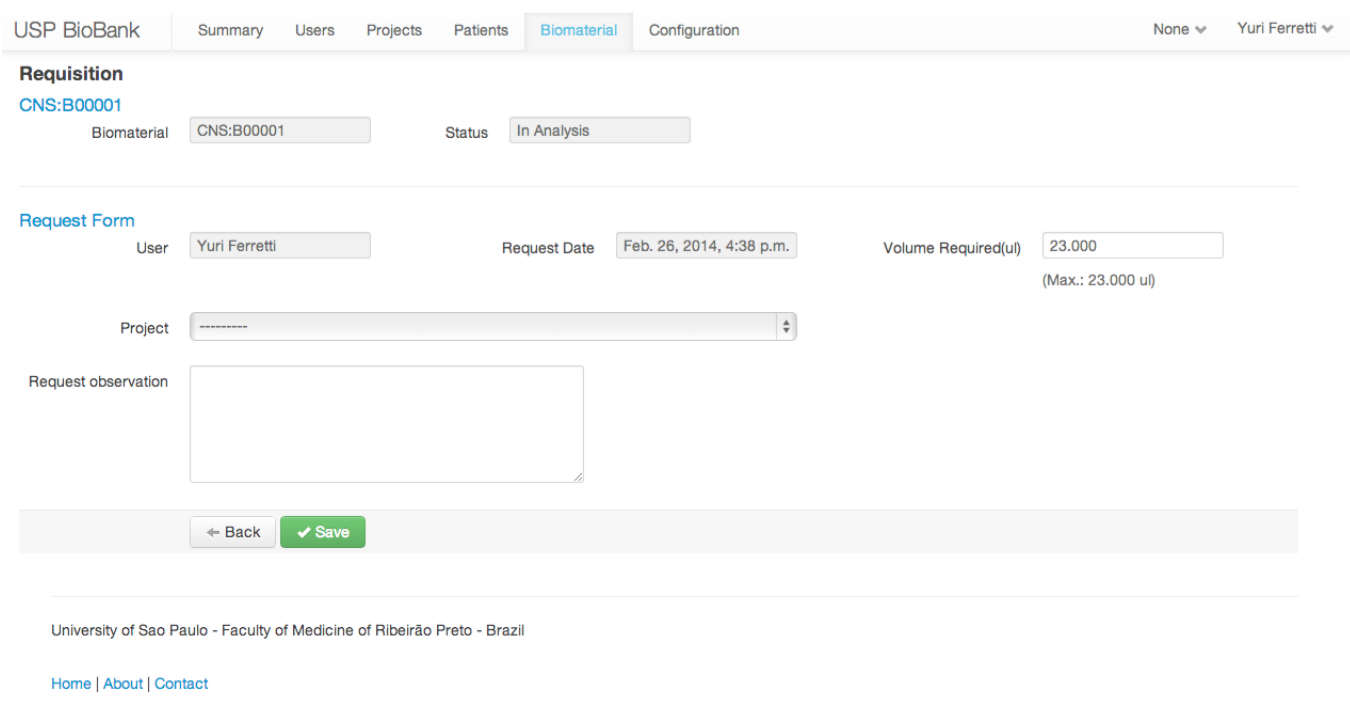

Figura 26 - Interface de requisição de alíquota de biomaterial

Outra possibilidade é que cada biomaterial, alíquota, ou sub-alíquota podem ter seus dados exibidos mais detalhadamente como pode ser visto na figura 27. Do lado esquerdo da interface pode-se observar uma árvore cuja raiz é o biomaterial que o usuário deseja visualizar os dados, e cada nó subsequente representa as sub-alíquotas desse biomaterial.

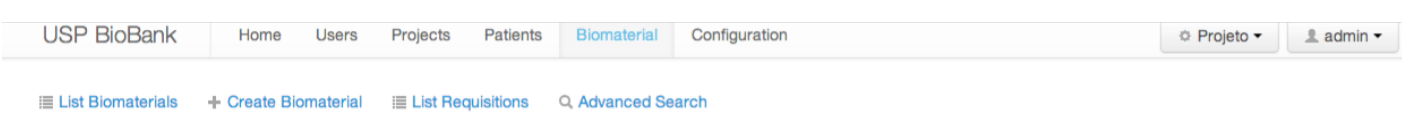

\section{Biomateral Details}

CNS:B00001

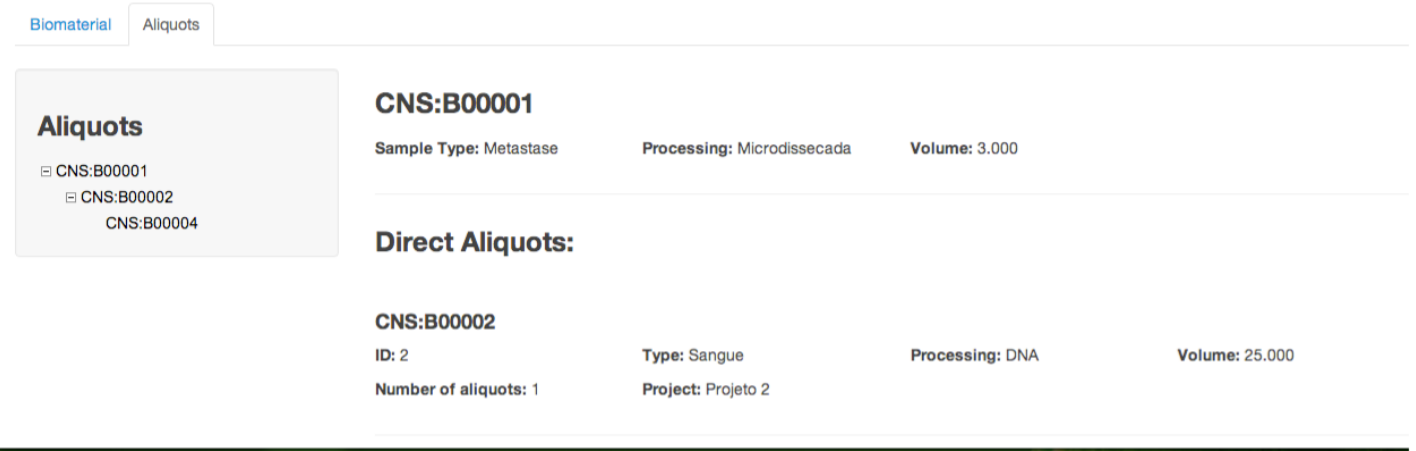

Figura 27 - interface detalhando as informações do biomaterial. Na esquerda está presente uma árvore composta pelo biomaterial e suas sub-alíquotas. 


\section{Avaliação de usabilidade dos usuários}

Para avaliar a usabilidade do BioBank Warden, foi proposta a aplicação de um questionário contendo perguntas sobre a usabilidade geral do sistema. Este questionário tem como intuito averiguar se o sistema é fácil de usar e atende as necessidades de seus possíveis usuários. Para isso foram convidados três usuários do sistema e foi aplicado o mesmo questionário descrito na seção 6.1.

Da mesma forma como na avaliação do IPTrans A2Tool, as questões puderam ser respondidas com valores variando de 1 até 7 , sendo que o número 1 significa que o usuário discorda fortemente enquanto 7 significa que o usuário concorda fortemente. Além dos números também está disponível a opção "não se aplica", usada quando o usuário não sabe opinar a respeito da pergunta. A seguir é exibida uma tabela com o resultado das questões para cada usuário.

Tabela 6 - Tabela com os resultados obtidos para cada usuário que respondeu o questionário.

\begin{tabular}{|l|c|c|c|}
\hline \multicolumn{1}{|c|}{} & \multicolumn{2}{|c|}{ Respostas } \\
\hline $\mathbf{1}$ & Usuário 1 & Usuário 2 & Usuário 3 \\
\hline $\mathbf{2}$ & 6 & 6 & 6 \\
\hline $\mathbf{3}$ & 6 & 7 & 7 \\
\hline $\mathbf{4}$ & 7 & 7 & 6 \\
\hline $\mathbf{5}$ & 7 & 7 & 7 \\
\hline $\mathbf{6}$ & 5 & 7 & 7 \\
\hline $\mathbf{7}$ & $\mathrm{NA}$ & 6 & 7 \\
\hline $\mathbf{8}$ & 7 & 6 & 7 \\
\hline $\mathbf{9}$ & 7 & 7 & 7 \\
\hline $\mathbf{1 0}$ & 5 & 7 & 7 \\
\hline $\mathbf{1 1}$ & 7 & 7 & 7 \\
\hline $\mathbf{1 2}$ & 7 & 7 & 7 \\
\hline
\end{tabular}

Como pode ser percebido analisando os dados da tabela, o sistema apresenta, na visão dos usuários que participaram do questionário, um nível bastante satisfatório de usabilidade. 


\section{Capítulo 7 - Conclusões}

Como o esperado, este trabalho conseguiu implementar o IPTrans A2Tool, uma ferramenta para analisar os dados armazenados e previamente integrados pelo framework IPTrans. Para o teste e validação da ferramenta, a mesma utilizou bases públicas do TCGA e também uma base legada armazenada no sistema BioBank Warden, também desenvolvido em conjunto com a ferramenta IPTrans A2Tool.

Ao compararmos as funcionalidades do IPTrans A2Tool com outras ferramentas apresentadas ao longo desta dissertação, podemos constatar que o objetivo de oferecer métodos de análise avançada como expressão diferencial entre genes e extração de regras de associação entre características clinicas e biomoleculares, foi atingido de forma satisfatória sem prejudicar o grau de expertise necessário ao usuário para realizar suas tarefas.

O IPTrans A2Tool, por meio dos testes de usabilidade aplicados em alguns usuários convidados, conseguiu demonstrar que suas funcionalidades facilitam o processo de análise de dados clínicos e biomoleculares realizados por um usuário sem conhecimento avançado em ferramentas de bioinformática. Isto permite que um número maior usuários possa realizar análises e ampliar o número de descobertas na área de medicina translacional.

Além do IPTrans A2Tool, foi desenvolvido um sistema de gerenciamento de dados clínicos e amostras biomoleculares, o BioBank Warden. Este sistema foi utilizado como base de dados legada e integrado ao IPTrans A2Tool com o intuito disponibilizar seus dados para serem analisados pela ferramenta IPTrans A2Tool.

Os recursos implementados pelo sistema BioBank Warden se mostram importantes para o trabalho cotidiano de pesquisadores de doenças relacionadas ao câncer, pois permite a agregação dos dados clínicos e controle de amostras biomoleculares em um só ambiente, o que facilita o desenvolvimento de pesquisas nesta área. Além disso, o trabalho permite o compartilhamento de dados e amostras entre projetos de pesquisa, fortalecendo ainda mais o papel da medicina translacional nos estudos genômicos relacionados ao câncer. 
Como trabalhos futuros, pode-se iniciar a implementação de mais ferramentas de análise no framework IPTrans A2Tool, além da possibilidade de se comparar mais de dois grupos. Para o sistema BioBank Warden, pretende-se incluir mais questionários clínicos voltados para outras especialidades além de cabeça e pescoço. 


\section{Referências Bibliográficas}

ABU-JAMOUS, Basel et al. Paradigm of Tunable Clustering Using Binarization of Consensus Partition Matrices (Bi-CoPaM) for Gene Discovery. Plos One, [s.l.], v. 8, n. 2, p.4-10. Public Library of Science (PLoS). (2013) DOI: 10.1371/journal.pone.0056432.

AGRAWAL, R. et al. Automatic Subspace Clustering of High Dimensional Data. Data Mining And Knowledge Discovery, [s.l.], v. 11, n. 1, p.5-33. Springer Science + Business Media. (2005) DOI: 10.1007/s10618-005-1396-1.

AGRAWAL, R.; IMIELIńSKI, T.; SWAMI, A. Mining association rules between sets of items in large databases.Proceedings Of The 1993 Acm Sigmod International Conference On Management of Data - Sigmod '93, [s.l.], p.207-216. Association for Computing Machinery (ACM). (2013) DOI: 10.1145/170035.170072.

BENJAMINI, Y.; HOCHBERG, Y. Controlling the false discovery rate: a practical and powerful approach to multiple testing. Journal of the Royal Statistical Society, Series B (1995)(1): 289-300. MR 1325392

CUI, X.; CHURCHILL, G. Statistical tests for differential expression in cDNA microarray experiments. Genome Biol, [s.l.], v. 4, n. 4, p.4-4. Springer Science Business Media.(2003) DOI: $10.1186 / \mathrm{gb}-2003-4-4-210$.

ELMASRI, R.; NAVATHE, S. Fundamentals of Database Systems. (2011) http://scholar.google.com/scholar?hl=en\&btnG=Search\&q=intitle:Fundamentals+of+Da $\mathrm{t}$ abase+Systems\#0.

FAGERLAND, M. W. T-tests, non-parametric tests, and large studies - a paradox of statistical practice? Bmc Med Res Methodol, [s.l.], v. 12, n. 1, p.12-78. Springer Science Business Media. (2012) DOI: 10.1186/1471-2288-12-78.

FELDMAN, A. Does academic culture support translational research? CTS: Clinical and Translational Science. (2008).

HOLOVATY, A.; KAPLANTMOSS J. The Definitive Guide to Django: Web Development Done Right (2009) (2): Apress. 500

KRASNER, G.; POPE, S. A Cookbook for Using the Model-View-Controller User Interface Paradigm in Smalltalk T80, Journal Of Object Oriented Programming (1988)

LI, W. VOLCANO PLOTS IN ANALYZING DIFFERENTIAL EXPRESSIONS WITH mRNA MICROARRAYS. Journal Of Bioinformatics And Computational Biology, [s.l.], v. 10, n. 06, p.1-2. World Scientific Pub Co Pte Lt. (2012) DOI: 10.1142/s0219720012310038. 
LOWE, H. J. et al. STRIDE - An integrated standard-based translational research informatics platform. AMIA - Annual Symposium proceedings / AMIA Symposium. AMIA Symposium (2009); 2009: 391T5.

MADHAVAN, S. et al. Rembrandt: Helping personalized medicine become a reality through integrative translational research. Molecular Cancer Research (2009);7(2):15767.

MCCONELL et. al. The cancer translational research informatics platform. BMC Medical Informatics and Decision Making (2008); 8:60.

MIYOSHI, N. S. B. Genômica translacional: integrando dados clínicos e biomoleculares. 2013. Dissertação (Mestrado em Bioinformática) - Bioinformática, University of São Paulo, São Paulo (2013). Disponível <http://www.teses.usp.br/teses/disponiveis/95/95131/tde-18072013-100518/>. Acesso em: 2015-11-02.

MIYOSHI, N. S. B. et al. Computational framework to support integration of biomolecular and clinical data within a translational approach. BMC Bioinformatics (2013) 14:180.

MUNGALL, C. J.; EMMERT, D. B. A Chado case study: an ontology-based modular schema for representing genome-associated biological information. Bioinformatics, [s.l.], v. 23, n. 13, p.337-346. Oxford University Press (OUP). (2007) DOI: 10.1093/bioinformatics/btm189.

MURPHY, S. N. et al. Architecture of the open-source clinical research chart from Informatics for Integrating Biology and the Bedside. AMIA - Annual Symposium proceedings / AMIA Symposium. AMIA Symposium (2007).

PAYNE, P.R. et. al. Breaking the translational barriers: The value of integrating biomedical informatics and translational research. Journal of Investigative Medicine. (2005);53(4):192-200.

RHODES, D. R. et al. ONCOMINE: a cancer microarray database and integrated datamining platform. Neoplasia (2004). 1: 1-6

STEIN, L. D.; THIERRYTMIEG J. AceDB: a genome database management system. Computing in Science \& Engineering (1999); (1) 3 : 44T52.

VAN ROSSUM, G.; and DRAKE, F. L. JR. The Python Language Reference Manual (version 2.5) (2011): Network Theory Limited. 142.

VIANGTEERAVAT, T.; BROOKS I. M.; SMITH E. J. et al. Slim-prim: a biomedical informatics database to promote translational research. Perspectives in health information management / AHIMA, American Health Information Management Association (2009); (6):6. 
VIDAL, V. et al. An Ontology-Based Framework for Geographic Data Integration. Berlin, Heidelberg: Springer Berlin Heidelberg (2009). v. 5833p. 337-346

ZHANG, C. 2002. Association Rule Mining: Models and Algorithms. Springer- Verlag. (2012) http://dl.acm.org/citation.cfm?id=1791549. 